Article

\title{
Conditional Dependence between Oil Prices and Exchange Rates in BRICS Countries: An Application of the Copula-GARCH Model
}

\author{
Yijin He and Shigeyuki Hamori * \\ Graduate School of Economics, Kobe University, 2-1, Rokkodai, Kobe 657-8501, Japan; heheyijin@yahoo.co.jp \\ * Correspondence: hamori@econ.kobe-u.ac.jp
}

Received: 21 April 2019; Accepted: 6 June 2019; Published: 9 June 2019

\begin{abstract}
We studied the dependence structure between West Texas Intermediate (WTI) oil prices and the exchange rates of BRICS ${ }^{1}$ countries, using copula models. We used the Normal, Plackett, rotated-Gumbel, and Student's $t$ copulas to measure the constant dependence, and we captured the dynamic dependence using the Generalized Autoregressive Score with the Student's t copula. We found that negative dependence and significant tail dependence exist in all pairs considered. The Russian Ruble (RUB)-WTI pair has the strongest dependence. Moreover, we treated five exchange rate-oil pairs as portfolios and evaluated the Value at Risk and Expected Shortfall from the time-varying copula models. We found that both reach low values when the oil price falls sharply.
\end{abstract}

Keywords: exchange rate; oil price; BRICS; dependence structure; copula

\section{Introduction}

Crude oil, as a non-renewable resource and a crucial commodity, plays a significant role in the world's economy. Over the past few decades, the crude oil price has experienced great fluctuations compared to the period from the Second World War to the early 1970s. For example, in June 2014, the West Texas Intermediate (WTI) crude oil price reached a peak of 105 US dollars per barrel, and then fell sharply to 59 US dollars per barrel in December 2014. In the early 1980s, many studies pointed out that oil price dynamics influenced economic activity (Hamilton 1983; Gisser and Goodwin 1986; Mork 1989). On the other hand, currency markets have also suffered multiple crises in recent years, such as the Latin American currency crisis of 1994, the Asian financial crisis of 1997, and most recently the fluctuation in the exchange rate between the US dollar and Chinese Yuan after a trade war, as each country continued to dispute tariffs in 2018. With these notable events, every abnormal foreign exchange movement had a huge impact on the economy. Analyzing the relationship between crude oil prices and exchange rates yields considerable information about the increasing importance of oil and currency markets in economics for market operators, investors, and economists.

On the theoretical side, the extant literature (Bénassy-Quéré et al. 2007; Bodenstein et al. 2011; Habib et al. 2016; Beckmann et al. 2017) has pointed out that there are three channels between oil price shocks and exchange rates: the terms of trade channel, wealth effects channel, and portfolio reallocation channel. The terms of trade channel considers a simple two-country open economy static model, which has two goods sectors-a traded goods sector and a non-traded goods sector. When there is a positive term of trade shock, the price of a basket of traded goods or non-traded goods in the domestic economy is relatively higher than it is in a foreign economy, leading to the appreciation of

1 BRICS is the acronym of an association of five major emerging economies: Brazil, Russia, India, China and South Africa. 
domestic currency. Hence, when oil prices rise, the currency of an energy-dependent country will appreciate, and vice versa. The wealth effects channel reflects the short-term effects while the portfolio reallocation channel reflects the medium- and long-term effects. When there is a positive oil price shock, the wealth transfers from the oil-importing country to the oil-exporting country, leading to large shifts in current account balances and portfolio reallocation. For this purpose, in order to adjust to clear the trade balance and asset markets, the currency of the oil-exporting country appreciates, and the currency of oil-importing country depreciates. Chen and Chen (2007) provide a simple model to illustrate the above theory:

$$
\begin{gathered}
\mathbf{p}=\alpha \mathbf{p}^{\mathbf{T}}+(\mathbf{1}+\boldsymbol{\alpha}) \mathbf{p}^{\mathbf{N},} \\
\mathbf{p}^{*}=\boldsymbol{\alpha}^{*} \mathbf{p}^{\mathbf{T} *}+\left(\mathbf{1}+\boldsymbol{\alpha}^{*}\right) \mathbf{p}^{\mathbf{N} *},
\end{gathered}
$$

where $\mathrm{p}\left(\mathrm{p}^{*}\right)$ is the log-linear approximation of the domestic (foreign) consumer price index, and $\mathrm{p}^{\mathrm{T}}$ $\left(\mathrm{p}^{\mathrm{T}^{*}}\right)$ and $\mathrm{p}^{\mathrm{N}}\left(\mathrm{p}^{\mathrm{N}^{*}}\right)$ are the prices of the traded and non-traded sectors in the home country (foreign country), respectively. The $\alpha\left(\alpha^{*}\right)$ weights correspond to expenditure shares on traded goods near the point of approximation for the domestic (foreign) country. The log of the real exchange rate $q$ is defined as

$$
\mathbf{q}=\mathbf{s}+\mathbf{p}-\mathbf{p}^{*},
$$

where $s$ is the log of the nominal exchange rate. Therefore, the real exchange rate could be written as

$$
\mathbf{q}=\left(\mathbf{s}+\mathbf{p}^{\mathbf{T}}-\mathbf{p}^{\mathbf{T} *}\right)+(\mathbf{1}-\boldsymbol{\alpha})\left(\mathbf{p}^{\mathbf{N}}-\mathbf{p}^{\mathbf{T}}\right)-\left(\mathbf{1}-\boldsymbol{\alpha}^{*}\right)\left(\mathbf{p}^{\mathbf{N} *}-\mathbf{p}^{\mathbf{T}}\right)
$$

If $\alpha \simeq \alpha^{*}$, when the oil price rises, the price of the traded sector in the country which is more dependent on oil importation will increase, and thereby cause a depreciation. ${ }^{2}$

On the empirical side, there are also many studies that investigate the relationship between oil prices and exchange rates. Some of this literature finds a negative relationship. Akram (2009) uses quarterly data from 1990Q1 to 2007Q4, and a structural value at risk (VaR) model to analyze whether a decline in the US dollar contributes to higher commodity prices. Their results suggest that a weaker dollar leads to higher commodity prices, including oil prices. Basher et al. (2012) study the dynamic relationship between oil prices, exchange rates, and emerging market stock prices by modeling daily data from 1988 to 2008 using a structural VaR model. They find that positive shocks to oil prices lead to an immediate drop in the US dollar exchange rate, which has a statistically significant impact in the short-run. Reboredo and Rivera-Castro (2013) use a wavelet decomposition approach to investigate the relationship between oil prices (WTI) and US dollar exchange rates for a large set of currencies, including developed and emerging economies, net oil-exporting and oil-importing economies, and inflation-targeting countries. They find that oil price changes had no effect on exchange rates or vice versa in the pre-crisis period, but after the 2008 global financial crisis, they find a negative interdependence. By contrast, other research finds a positive relationship between oil prices and exchange rates. Bénassy-Quéré et al. (2007) study co-integration and causality between the real price of oil and the real value of the dollar from 1974 to 2005 using monthly data. Their results suggest that a 10\% rise in the oil price coincides with a $4.3 \%$ appreciation of the dollar in the long run, and the causality runs from oil to the dollar. Ding and Vo (2012) use the multivariate stochastic volatility and the multivariate generalized autoregressive conditional heteroscedasticity (GARCH) models to investigate the volatility interactions between the oil market and the foreign exchange market. They divided the data into two parts to capture the structural breaks in the economic crisis, and they show that before the 2008 crisis, the two markets responded to shocks simultaneously and no interaction is found. However, during the financial crisis, they find a positive bidirectional volatility interaction between the two variables.

2 For more detail, see Chen and Chen (2007). 
In addition to research in developed markets, other studies focus on this relationship in emerging markets. For example, Narayan et al. (2008) estimate the impact of oil prices on the nominal exchange rate on Fiji Island with GARCH and EGARCH ${ }^{3}$ models. They find that a rise in oil prices leads to an appreciation of the Fijian dollar. Narayan (2013) uses exchange rate data from 14 Asian countries and demonstrates that a higher oil price leads to a future depreciation of the Vietnamese Dong, but a future appreciation of the local currencies of Bangladesh, Cambodia, and Hong Kong.

Analysis of the correlation between the currency and oil markets also provides abundant information about whether the oil price could act as a hedge or as a safe haven against exchange rate risk. Much literature investigates the relationship between different assets to examine whether these variables act as hedges against each other. The methods used in these papers are varied, such as linear regression, quantile regression, etc. Considering that the characteristics of skew and leptokurtic kurtosis often have asymmetric behaviors, and the oil price and exchange rates seem unsuitable for modeling with linear models, in this study, we propose a copula model to investigate the dependency between oil prices and exchange rates. Compared to traditional methods, a copula model has several advantages. First, it can provide a valid joint distribution in combination with any univariate distribution, which makes it more flexible in modeling multivariate distributions. Second, it can capture a wide range of dependence structures, such as asymmetric, nonlinear, and tail dependence in extreme events. Prior studies apply copula models to examine the relationship between oil prices and exchanges rates (Patton 2006; Wu et al. 2012; Aloui et al. 2013; Ji et al. 2019). However, most of them focus on developed markets.

In this study, we investigate the dependence structure between the oil and currency markets. Our contribution to the literature is twofold. First, we propose both constant and time-varying copula-GARCH-based models to measure the dependence between the two markets elastically. By using a copula model, we can study the co-movement between oil prices and exchange rates during bearish and bullish markets, and we can also examine whether oil acts as a hedge against exchange rate risk in BRICS countries. Second, we focus on exchange rate data from the BRICS countries, which is a group of five developing countries (Brazil, Russia, India, China, and South Africa), to determine whether the dependence structure in emerging markets is the same as that in developed countries.

The rest of this paper proceeds as follows. In Section 2, we introduce the empirical methodology and estimation strategy. Section 3 presents the data and discusses the empirical results. In the final section, we present our conclusions. The results of ARMA-GARCH model and the robustness analysis are presented in Appendices A and B, respectively.

\section{Empirical Methodology}

Sklar (1959) introduced the notion of the copula, in which an n-dimensional distribution function which can be decomposed into two parts, namely, the marginal distribution and the copula.

We denote $X \equiv\left[X_{1}, \ldots, X_{n}\right]^{\prime}$ as the variable set of interest, and $X_{i}$ follows the marginal distribution $F_{i}$ for each $i \in[0, n]$.

$$
\mathrm{F}_{\mathrm{i}}\left(\mathrm{x}_{\mathrm{i}}\right)=\mathrm{P}\left(\mathrm{X}_{\mathrm{i}} \leq \mathrm{x}_{\mathrm{i}}\right)
$$

Following Sklar's theorem, there exists a copula $C:[\mathbf{0}, \mathbf{1}]^{\mathbf{n}} \rightarrow[\mathbf{0}, \mathbf{1}]$ with uniform marginals that can map the univariate marginal distribution $\mathrm{F}_{\mathrm{i}}$ to the multivariate distribution function $\mathrm{F}$.

$$
\mathbf{F}\left(\mathrm{x}_{1}, \ldots \mathrm{x}_{\mathrm{n}}\right)=\mathrm{C}\left(\mathrm{F}_{1}\left(\mathrm{x}_{1}\right), \ldots, \mathrm{F}_{\mathrm{n}}\left(\mathrm{x}_{\mathrm{n}}\right)\right)
$$

The density of the multivariate distribution function $\mathrm{F}$ is

$$
f\left(x_{1}, \ldots x_{n}\right)=c\left(F_{1}\left(x_{1}\right), \ldots, F_{n}\left(x_{n}\right)\right) \times f_{1}\left(x_{1}\right) \times \ldots \times f_{n}\left(x_{n}\right)
$$

3 EGARCH is an abbreviation for Exponential Generalized Autoregressive Conditional Heteroscedastic. EGARCH model was introduced by Nelson (1991). 
We first obtain standardized residuals using an autoregressive moving-average GARCH (ARMA-GARCH) model for the daily returns of crude oil prices and exchange rates. Then, we transform the standardized residuals into a uniform distribution. Finally, we input the transformed uniform variates into the copula function to model the dependence structure.

\subsection{ARMA-GARCH Model}

To model the daily returns of crude oil prices and exchange rates, we use autoregressivemoving-average (ARMA) models with two kinds of GARCH models--the standard GARCH (sGARCH) model and the Glosten-Jagannathan-Runkle GARCH (GJR-GARCH) model. In both GARCH models, we assume that the standard errors from the GARCH models follow a skewed $t$ distribution.

We denote $r_{t}$ as the daily returns, which follow

$$
\mathrm{r}_{\mathrm{t}}=\phi_{0}+\sum_{\mathrm{i}=1}^{\mathrm{p}} \phi_{\mathrm{i}, 1} \mathrm{r}_{\mathrm{t}-\mathrm{i}}+\sum_{\mathrm{j}=1}^{\mathrm{q}} \phi_{\mathrm{j}, 2} \varepsilon_{\mathrm{t}-\mathrm{j}}+\varepsilon_{\mathrm{t}},
$$

where $\phi_{0}$ is a constant and $\varepsilon_{\mathrm{t}}$ is a white noise error item. Table 1 presents the functions for the two GARCH models.

Table 1. Generalized autoregressive conditional heteroscedasticity (GARCH) model functions.

\begin{tabular}{cc}
\hline Type & Function \\
\hline sGARCH & $\varepsilon_{\mathrm{t}}=\sigma_{\mathrm{t}} \mathrm{z}_{\mathrm{t}}$ \\
& $\sigma_{\mathrm{t}}^{2}=\omega+\alpha \varepsilon_{\mathrm{t}-1}+\beta \sigma_{\mathrm{t}-1}^{2}$ \\
\hline GJR-GARCH & $\varepsilon_{\mathrm{t}}=\sigma_{\mathrm{t}} \mathrm{z}_{\mathrm{t}}$ \\
& $\sigma_{\mathrm{t}}^{2}=\omega+\left(\alpha+\gamma \mathrm{I}_{\mathrm{t}-1}\right) \varepsilon_{\mathrm{t}-1}^{2}+\beta \sigma_{\mathrm{t}-1}^{2}$ \\
& $\mathrm{I}_{\mathrm{t}-1}=\left\{\begin{array}{l}0 \text { if } \mathrm{r}_{\mathrm{t}-1} \geq \mu \\
1 \text { if } \mathrm{r}_{\mathrm{t}-1}<\mu\end{array}\right.$ \\
\hline
\end{tabular}

Note: this table presents the functions of the GARCH model and the Glosten-Jagannathan-Runkle GARCH (GJR-GARCH) model. $\varepsilon_{\mathrm{t}}$ is a zero-mean white noise item, which is assumed to follow a skewed $\mathrm{t}$ distribution, $\mu$ is the expected return, and $z_{t}$ is an i.i.d (independent and identically distributed). random variable with zero mean and a variance of one.

\subsection{Marginal Distribution}

Following Patton (2013), we consider both parametric and non-parametric models in modeling the marginal distribution.

For the parametric estimation, we choose the skewed t distribution as in Hansen (1994). The density function is

$$
\begin{gathered}
f(\varepsilon)=\left\{\begin{array}{cc}
\mathrm{bc}\left(1+\frac{1}{v-2}\left(\frac{\mathrm{b} \varepsilon+\mathrm{a}}{1-\lambda}\right)^{2}\right)^{-(v+1) / 2} & \varepsilon<-\mathrm{a} / \mathrm{b} \\
\mathrm{bc}\left(1+\frac{1}{v-2}\left(\frac{\mathrm{b} \varepsilon+\mathrm{a}}{1+\lambda}\right)^{2}\right)^{-(v+1) / 2} & \varepsilon \geq-\mathrm{a} / \mathrm{b}
\end{array}\right. \\
\mathrm{a}=4 \lambda \mathrm{c}\left(\frac{v-2}{v-1}\right), \\
\mathrm{b}^{2}=1+3 \lambda^{2}-\mathrm{a}^{2} \\
\mathrm{c}=\frac{G\left(\frac{v+1}{2}\right)}{\sqrt{\pi(v-2)} G\left(\frac{v}{2}\right)} .
\end{gathered}
$$

The skewed $t$ distribution has two parameters to control its shape: a skewness parameter $\lambda \in(-1,1)$, which determines whether the mode of the density is skewed to the left or to the right, and a degrees of freedom parameter $v \in(2, \infty)$, which controls the kurtosis of the distribution. When $\lambda=0$, we obtain the Student's t distribution; when $v \rightarrow \infty$, we obtain the skewed normal distribution; and when $\lambda=0$ with $v \rightarrow \infty$, we obtain the standard normal distribution. For this property, the skewed $t$ distribution has more flexibility in fitting the data than do the normal distribution or the Student's $t$ distribution.

For the non-parametric estimation, we use the empirical distribution function (EDF):

$$
\hat{\mathrm{F}}_{\mathrm{i}}(\varepsilon) \equiv \frac{1}{\mathrm{~T}+1} \sum_{\mathrm{t}=1}^{\mathrm{T}} 1\left\{\hat{\varepsilon}_{\mathrm{it}} \leq \varepsilon\right\},
$$


where $\mathrm{T}$ is the length of the data and $\hat{\varepsilon}_{\mathrm{it}}$ indicates the standardized residuals from the GARCH model.

\subsection{Copula Model}

\subsubsection{Constant Copula Model}

There are three families of copula model: elliptical copulas (Normal and Student's t); Archimedean copulas (Gumbel, Clayton, and Frank); and quadratic copulas (Plackett). In this study, we chose the Normal, Plackett, Rotated Gumbel, and Student's t copulas to investigate the dependence structure between oil prices and exchange rates. ${ }^{4}$

The normal and Student's t copulas are based on an elliptical distribution, such as the normal or Student's $t$ distribution. The normal copula is symmetric and has no tail dependence. $\theta>0$ and $\theta<0$ lead to positive and negative dependence, respectively. The Student's t copula is also symmetric, but can capture tail dependence in extreme events. When $\theta_{1}=0$ with $\theta_{2} \rightarrow \infty$, then it becomes independent between the two variables. Like the Normal copula, the Plackett copula is also symmetric and cannot capture either lower or upper tail dependence. $0<\theta<1$ implies negative dependence and $\theta>1$ implies positive dependence. The Gumbel copula can only capture extreme lower dependence, $\theta=1$ and $\theta \rightarrow \infty$ indicate independence and perfectly negative dependence, respectively.

Table 2 summarizes the properties of the abovementioned bivariate copula models.

\subsubsection{Time-Varying Copula Model}

In this study, we examined the time-varying Student's t copula using a Generalized Autoregressive Score (GAS) model. Creal et al. (2013) proposed the GAS model, which provides a general framework for modeling time variation. We consider $\delta_{t}$ as the parameter vector of the time-varying copula models, which we can express as the following function:

$$
\delta_{\mathrm{t}}=\mathrm{h}\left(\mathrm{f}_{\mathrm{t}}\right)
$$

where $\mathrm{f}_{\mathrm{t}}$ is the time-varying parameter vector in the GAS model. Following Creal et al. (2013), we can assume that $\mathrm{f}_{\mathrm{t}}$ is given by the familiar autoregressive updating equation:

$$
\begin{gathered}
\mathrm{f}_{\mathrm{t}+1}=\omega+\alpha \mathrm{S}_{\mathrm{t}-1} \cdot \nabla_{\mathrm{t}}+\beta \mathrm{f}_{\mathrm{t}}, \\
\nabla_{\mathrm{t}}=\frac{\partial \operatorname{lnc}\left(\mathbf{u}_{\mathrm{t}} ; \mathrm{f}_{\mathrm{t}}\right)}{\partial \mathrm{f}_{\mathrm{t}-1}}, \\
\mathrm{f}_{\mathrm{t}}=\mathrm{h}^{-1}\left(\delta_{\mathrm{t}}\right),
\end{gathered}
$$

where $\omega$ is a constant, $S_{t-1}$ is a time-dependent scaling matrix, $\mathrm{c}(\cdot)$ is the density function of the copula model, and $u_{t}$ is the vector of the probability integral transforms using the univariate marginals. According to Creal et al. (2013), we can set the scaling matrix $\mathrm{S}_{\mathrm{t}-1}$ to be equal to the pseudo-inverse information matrix:

$$
\mathrm{S}_{\mathrm{t}-1}=\mathrm{I}_{\mathrm{t}-1}^{-1}=\mathrm{E}_{\mathrm{t}-1}\left[\nabla_{\mathrm{t}} \nabla_{\mathrm{t}}^{\prime}\right]^{-1}=-\mathrm{E}_{\mathrm{t}-1}\left[\frac{\partial^{2} \operatorname{lnc}\left(\mathbf{u}_{\mathrm{t}} ; \mathrm{f}_{\mathrm{t}}\right)}{\partial \mathrm{f}_{\mathrm{t}-1} \partial \mathrm{f}_{\mathrm{t}-1}^{\prime}}\right]^{-1} .
$$

For the time-varying Student's t copula, we use the function $\delta_{t}=\left[1-\exp \left(-f_{t}\right)\right] /\left[1+\exp \left(-f_{t}\right)\right]$ to ensure that the parameter lies within $(-1,1)$.

4 We used Normal, Clayton, rotated-Clayton, Plackett, Frank, Gumbel, rotated-Gumbel, SJC and Student's t copula models in our empirical analysis at first, but the log-likelihoods in the Clayton, Rotated-Clayton, Frank, Gumbel, rotated-Gumbel and SJC copulas are negative, which means that the dependence coefficients in these copula models are quiet low, so we only present the results of the Normal, Plackett, and Student's t copula models, which have a positive log-likelihood. The rotated-Gumbel copula has the lowest log-likelihood in most currency-oil price pairs, so we also present it in the paper for comparison. 
Table 2. Bivariate copula models.

\begin{tabular}{|c|c|c|c|c|}
\hline Type & Parameter(s) & Function & Lower Tail Dependence & Upper Tail Dependence \\
\hline Normal & $\theta \in(-1,1)$ & $\int_{-\infty}^{\Phi^{-1}\left(\mathrm{u}_{1}\right)} \int_{-\infty}^{\Phi^{-1}\left(\mathrm{u}_{2}\right)} \frac{1}{2 \pi \sqrt{1-\theta^{2}}} \exp \left(-\frac{\mathrm{s}^{2}-2 \theta s \mathrm{st} \mathrm{t}^{2}}{2\left(1-\theta^{2}\right)}\right) \mathrm{dsdt}$ & 0 & 0 \\
\hline Plackett & $\theta \in(0, \infty)$ & $\frac{1+(\theta-1)\left(\mathrm{u}_{1}+\mathrm{u}_{2}\right)-\left\{\left[1+(\theta-1)\left(\mathrm{u}_{1}+\mathrm{u}_{2}\right)\right]^{2}-4 \mathrm{u}_{1} \mathrm{u}_{2} \theta(\theta-1)\right\}^{1 / 2}}{2(\theta-1)}$ & 0 & 0 \\
\hline Rotated-Gumbel & $\theta \in(1, \infty)$ & $\exp \left\{-\left[\left(-\ln u_{1}^{\prime}\right)^{\theta}+\left(-\ln u_{2}^{\prime}\right)^{\theta}\right]^{1 / \theta}\right\}$ & $2-2^{1 / \theta}$ & 0 \\
\hline Student's t & $\begin{array}{l}\rho\left(\theta_{1}\right) \in(-1,1) \\
\nu\left(\theta_{2}\right) \in(2, \infty)\end{array}$ & $\int_{-\infty}^{\mathrm{t}^{-1}\left(\mathrm{u}_{1}\right)} \int_{-\infty}^{\mathrm{t}^{-1}\left(\mathrm{u}_{2}\right)} \frac{1}{2 \pi \sqrt{1-\rho^{2}}} \exp \left(-\frac{\mathrm{s}^{2}-2 \rho s \mathrm{t}+\mathrm{t}^{2}}{2\left(1-\mathrm{u}_{2}{ }^{2}\right)}\right)^{-\frac{\mathrm{u}_{2}+2}{2}} \mathrm{dsdt}$ & $2 \times F_{t}\left(-\sqrt{\left(u_{2}+1\right) \frac{\rho-1}{\rho+1}}, u_{2}\right)$ & $2 \times F_{t}\left(-\sqrt{\left(u_{2}+1\right) \frac{\rho-1}{\rho+1}}, u_{2}\right)$ \\
\hline
\end{tabular}

Note: this table presents the basic properties of the Normal, Plackett, rotated-Gumbel, and Student's t copula models. $\mathrm{u}_{1}$ and $\mathrm{u}_{2}$ are uniform variates. In the rotated-Gumbel copula, $\mathrm{u}_{1}{ }^{\prime}=1-\mathrm{u}_{1}, \mathrm{u}_{2}{ }^{\prime}=1-\mathrm{u}_{2} . \Phi^{-1}(\cdot)$ denotes the inverse cumulative distribution function of the univariate standard normal distribution, and $\mathrm{t}^{-1}(\cdot)$ indicates the inverse cumulative distribution function of the univariate Student's $t$ distribution. $F_{t}(\cdot)$ denotes the probability density function of the standard Student's $t$ distribution. This table is based on Aloui et al. (2013), Patton (2013) and Nelsen (2006). 


\section{Empirical Analysis}

\subsection{Data and Summary Statistics}

Our dataset contained the WTI oil prices in dollars and the nominal dollar-denominated exchange rates for the Brazilian Real (BRL), Russian Ruble (RUB), Indian Rupee (INR), Chinese Yuan (CNY), and South African Rand (ZAR). After 2000, China reformed its exchange rate regime twice. The first time was in 2005, when the authorities adopted a managed floating exchange rate system with reference to a basket of currencies, and the second time was in 2010, when the CNY shifted from a bilateral to a multilateral reference, with greater emphasis on the currency basket. Before each reform, $\mathrm{CNY}$ fluctuated with no change or within a narrow range. We thus chose the offshore exchange rate for CNY for our analysis. Our sample period was from 4 October 2010 to 11 December 2018, to match the data availability for the offshore $\mathrm{CNY}$ exchange rate. We downloaded all data from the DataStream database.

We obtained the stationary return series using the following function:

$$
r_{i, t}=100 \times \ln \left(\frac{p_{i, t}}{p_{i, t-1}}\right) .
$$

Since many events occurred during our sample period, such as China's central bank devaluation of its currency in 2015, the United Kingdom's vote to leave the European Union in 2016, etc., which may be directly or indirectly relevant to oil prices and exchange rates, we applied a methodology from Bai and Perron $(1998,2003)$ for testing the structural breaks, to avert unexpected changes in our dataset. The $p$-values of structural break tests on the return series are summarized in Table 3. The results showed an acceptance of the null hypothesis that there are no breaks, therefore we were able to use this sample period for further analysis.

Table 3. Structural break tests.

\begin{tabular}{cc}
\hline Variable & $\boldsymbol{p}$-Value \\
\hline BRL & 0.2970 \\
RUB & 0.3960 \\
INR & 0.2790 \\
CNY & 0.1969 \\
ZAR & 0.4307 \\
WTI & 0.4737
\end{tabular}

Note: this table presents the $p$-values of structural break tests using the methodology developed by Bai and Perron $(1998,2003)$.

Figure 1 shows the plot of the time-path of the return series, and Table 4 reports the descriptive statistics for daily returns. The mean of CNY is close to zero, and its standard deviation is the lowest of all return series. Thus, in some way, $\mathrm{CNY}$ remained stable under the government regulations. RUB has the most fluctuations among the five exchange rates, especially at the end of 2014, when the price of crude oil declined by nearly $50 \%$, which was a major cause of the financial crisis in Russia. All return series are skewed and have high kurtosis, indicating that the distributions of the return series show obvious non-normality characteristics. The Jarque-Bera test performed on the return series also verifies our analysis.

Before beginning the copula analysis, we provide the results of the rank correlation and linear correlation in Table 5 for comparison. All coefficients are significant, indicating negative relationships between all currency-oil pairs. The RUB-WTI pair has the highest coefficient for both the rank and linear correlations, possibly because Russia is the second largest oil-exporting country in the world, and Russia exports more oil than the other countries in our sample. 


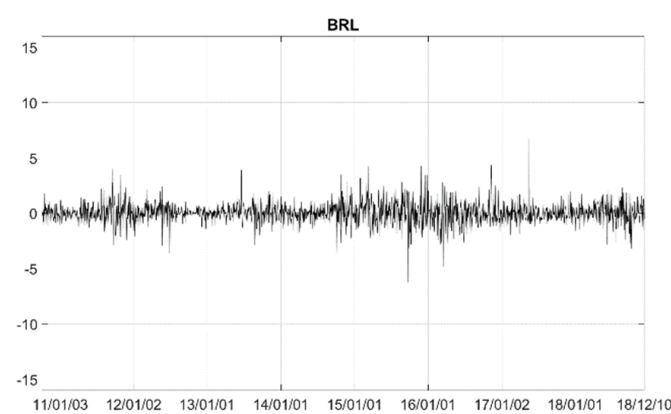

(a)

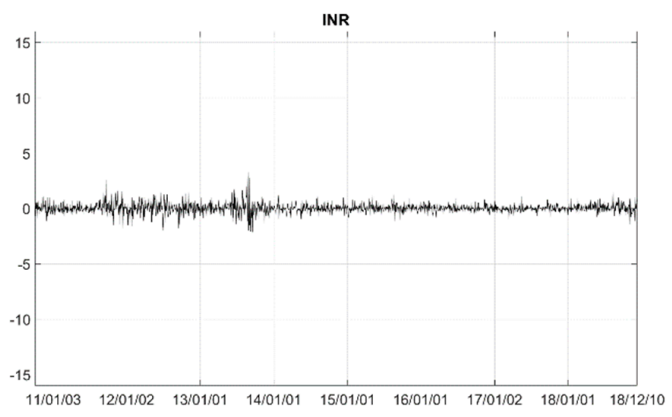

(c)

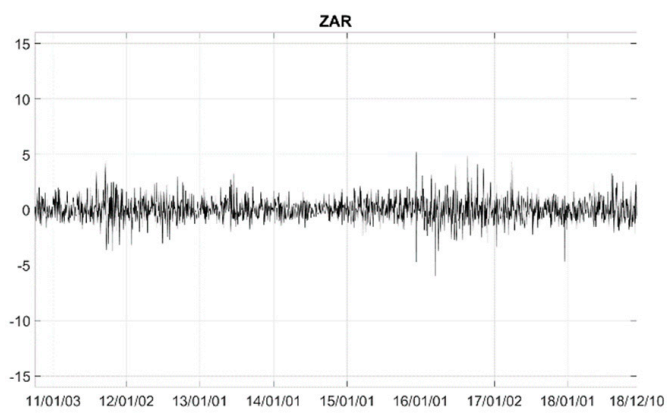

(e)

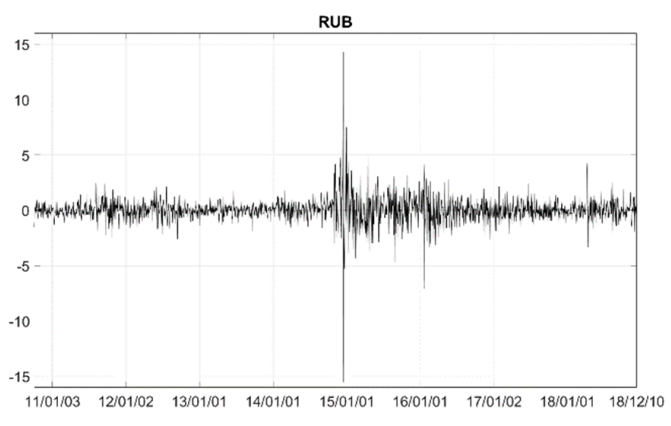

(b)

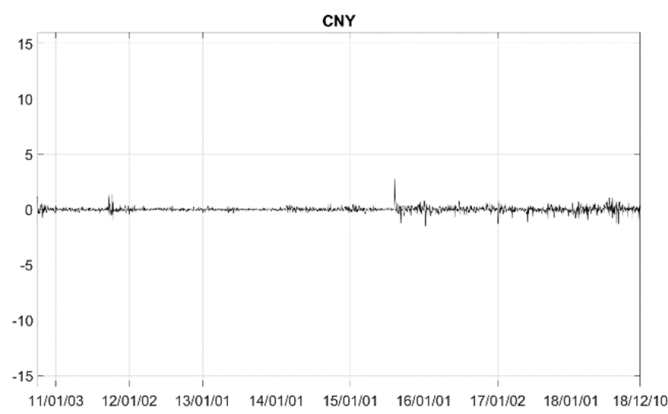

(d)

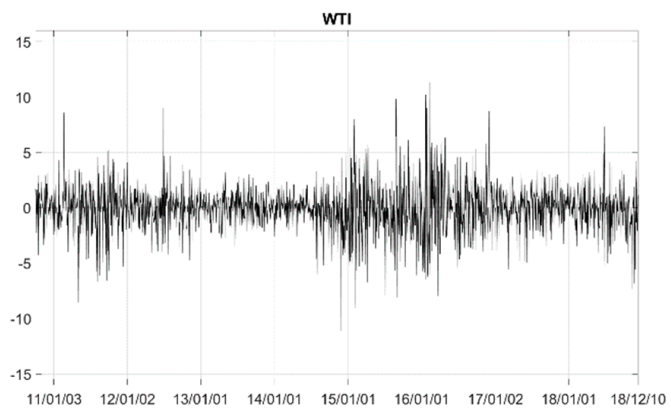

(f)

Figure 1. Daily returns on the exchange rates and crude oil prices. (a-f) refer to return series of BRL, RUB, INR, CNY, INR and WTI, respectively.

Table 4. Summary statistics.

\begin{tabular}{|c|c|c|c|c|c|c|}
\hline Max & Min & Mean & Std Dev & Skewness & Kurtosis & JB-test \\
\hline \multicolumn{7}{|c|}{$\mathrm{CNY}$} \\
\hline 2.7613 & -1.6089 & 0.0020 & 0.2306 & 0.4162 & 19.3577 & $23,875.7349^{* * *}$ \\
\hline \multicolumn{7}{|c|}{ BRL } \\
\hline 6.7177 & -6.2365 & 0.0394 & 0.9086 & 0.1419 & 7.5098 & $1817.2875^{* * *}$ \\
\hline \multicolumn{7}{|c|}{ RUB } \\
\hline 14.2683 & -15.5230 & 0.0365 & 1.0691 & 0.0078 & 43.8985 & $148,868.9913^{* * *}$ \\
\hline \multicolumn{7}{|c|}{ INR } \\
\hline 3.2513 & -2.1247 & 0.0223 & 0.4308 & 0.3526 & 8.5421 & $2777.8609 * * *$ \\
\hline \multicolumn{7}{|c|}{ ZAR } \\
\hline 5.2017 & -5.9939 & 0.0334 & 0.9905 & 0.2045 & 5.7404 & $683.2793^{* * *}$ \\
\hline \multicolumn{7}{|c|}{ WTI } \\
\hline 11.2892 & -11.1258 & -0.0213 & 2.0619 & 0.0411 & 6.2304 & $929.3830^{* * *}$ \\
\hline
\end{tabular}

Note: this table presents the summary statistics for the daily returns on BRICS countries' exchange rates and crude oil prices. The sample period is from 4 October 2010 to 11 December 2018. The JB-test refers to the Jarque-Bera test for normality. ${ }^{* * *}$ indicates a rejection of the null hypothesis, which states that the data is normally distributed at the $1 \%$ level of significance. 
Table 5. Rank correlation and linear correlation.

\begin{tabular}{cccc}
\hline Pair & Kendall's $\tau$ & Spearman's $\rho$ & Pearson \\
\hline CHY-WTI & $-0.1033^{* * *}$ & $-0.1536^{* * *}$ & $-0.1382^{* * *}$ \\
BRL-WTI & $-0.1543^{* * *}$ & $-0.2284^{* * *}$ & $-0.2383^{* * *}$ \\
RUB-WTI & $-0.2460^{* * *}$ & $-0.3576^{* * *}$ & $-0.3483^{* * *}$ \\
INR-WTI & $-0.0710^{* * *}$ & $-0.1064^{* * *}$ & $-0.1243^{* * *}$ \\
ZAR-WTI & $-0.1626^{* * *}$ & $-0.2396^{* * *}$ & $-0.2607^{* * *}$ \\
\hline
\end{tabular}

Note: this table represents the Kendall's $\tau$ correlation coefficient, which measures the strength of dependence between two variables; the Spearman's $\rho$ correlation coefficient, which measures the degree of association between two variables; and the Pearson correlation coefficient, which measures the degree of the relationship between linearly related variables. ${ }^{* * *}$ indicates significance at $1 \%$ level.

\subsection{Constant Copula Result}

Tables 6-10 report the estimations of the four constant copulas (Normal, Plackett, rotated-Gumbel, and Student's t) for five currency-oil price pairs (BRL-WTI, RUB-WTI, INR-WTI, CNY-WTI, and ZAR-WTI), respectively. The parameters from the copula model are estimated based on the maximum likelihood method. In all pairs, the Student's t copula has the highest value of log-likelihood, while the rotated-Gumbel copula has the lowest. Almost all estimated copula parameters are significant at the $1 \%$ level. The results of the copula models reveal a significant dependence between the oil price and exchange rates. All copula models suggest a negative dependence among all considered pairs, for both the parametric and semi-parametric cases, which could be because oil is considered as a hedge against inflation in BRICS countries. For oil-importing countries, like China, India, and South Africa, the negative dependence is in line with the theoretical method, which illustrates that the currency of an oil-importing country will depreciate when oil price goes up. This result is also in accordance with other studies, such as that of Ghosh (2011), who assesses the relationship between the Indian Rupee and oil price and finds the existence of a negative correlation. Kin and Courage (2014) find that an increase in oil prices leads to a depreciation of the South African rank exchange rate. However, for oil-exporting countries such as Russia and Brazil, the result is the opposite with the theoretical model. We still found some studies which have the same results as those found in our analysis, such as Blokhina et al. (2016), who find a negative relationship by applying a linear regression to Russia. In each copula model, the RUB-WTI pair has the highest dependence coefficient, followed by ZAR-WTI, BRL-WTI, CNY-WTI, and INR-WTI, which is consistent with the rank and linear correlation results.

According to Genest et al. (2009), the Cramer-von Mises (CvM) test is the most powerful test to check the goodness-of-fit of copula models. Here, we used both the CvM test and the Kolmogorov-Smirnov (KS) test to check the quality of the data fit. We defined the CvM and KS tests for the bivariate case as:

$$
\begin{gathered}
\hat{\mathbf{C}}(\mathbf{u}) \equiv \frac{1}{\mathrm{~T}} \sum_{\mathrm{t}=1}^{\mathrm{T}} \prod_{\mathrm{j}=1}^{\mathrm{n}} \mathbf{1}\left\{\hat{\mathrm{U}}_{\mathrm{it}} \leq \mathrm{u}_{\mathrm{j}}\right\} \forall \mathrm{i}=1,2, \\
\mathrm{CvM}=\sum_{\mathrm{t}=1}^{\mathrm{T}}\left\{\mathrm{C}\left(\mathrm{U}_{\mathrm{it}} ; \theta\right)-\hat{\mathrm{C}}\left(\mathrm{U}_{\mathrm{it}}\right)\right\}^{2} \forall \mathrm{i}=1,2, \\
\mathrm{KS}=\max _{\mathrm{t}}\left|\mathrm{C}\left(\mathrm{U}_{\mathrm{it}} ; \theta\right)-\hat{\mathrm{C}}\left(\mathrm{U}_{\mathrm{it}}\right)\right| \forall \mathrm{i}=1,2 .
\end{gathered}
$$


Table 11 presents the $p$-values of the goodness-of-fit test. For all pairs, the rotated-Gumbel copula is rejected at the $1 \%$ level of significance, except for in the parametric case of INR-WTI. The Student's $t$ copula generates the highest $p$-value in most cases, indicating that it provides the best fit for the data.

Tail dependence describes co-movements between two variables during extreme events. In our case, lower tail dependence measures the probability of currency depreciation when the oil price falls. In contrast, upper tail dependence measures the probability of currency appreciation when the oil price rises. In Table 12, we present the tail dependence coefficients from the constant Student's t copula model, which can capture symmetrical tail dependence. The results show significant extreme market co-movements between the exchange rate and oil price. INR-WTI has the highest tail dependence, while RUB-WTI has the lowest for both the parametric and semi-parametric cases.

Table 6. Constant copula parameter estimation (Brazilian Real—BRL).

\begin{tabular}{|c|c|c|c|c|}
\hline \multirow{2}{*}{ Type } & \multicolumn{2}{|l|}{ Parametric } & \multicolumn{2}{|c|}{ Semi-Parametric } \\
\hline & $\hat{\theta}$ & $\log \zeta$ & $\hat{\theta}$ & $\log \zeta$ \\
\hline Normal & $\begin{array}{l}-0.2396^{* * *} \\
(0.0201)\end{array}$ & 63.3962 & $\begin{array}{l}-0.2384^{* * *} \\
(0.0221)\end{array}$ & 62.4599 \\
\hline Plackett & $\begin{array}{c}0.4930^{* * *} \\
(0.0367)\end{array}$ & 58.7756 & $\begin{array}{l}0.4948^{* * *} \\
(0.0320)\end{array}$ & 58.3472 \\
\hline Rotated-Gumbel & $\begin{array}{l}1.1000^{* * *} \\
(0.0044)\end{array}$ & -94.1647 & $\begin{array}{l}1.1000^{* * *} \\
(0.0103)\end{array}$ & -94.4560 \\
\hline Student's t $\left(\rho, v^{-1}\right)$ & $\begin{array}{cc}-0.2403^{* * *} & 0.0309^{* *} \\
(0.0218) & (0.0156)\end{array}$ & 64.4623 & $\begin{array}{cl}-0.2398 * * * & 0.0301 * \\
(0.0202) & (0.0205)\end{array}$ & 63.4614 \\
\hline
\end{tabular}

Note: this table presents the constant copula estimation results for the BRL-WTI pair. $\hat{\theta}$ is the estimated coefficient. $\log \zeta$ represents the log-likelihood of each constant copula model. The values in parentheses are the standard error of the parameter. The values in bold indicate the highest log-likelihood values. ${ }^{*}, *$, and ${ }^{* * *}$ indicate significance at the $10 \%, 5 \%$, and $1 \%$ levels, respectively.

Table 7. Constant copula parameter estimation (Russian Ruble-RUB).

\begin{tabular}{|c|c|c|c|c|}
\hline \multirow{2}{*}{ Type } & \multicolumn{2}{|l|}{ Parametric } & \multicolumn{2}{|c|}{ Semi-Parametric } \\
\hline & $\hat{\theta}$ & $\log \zeta$ & $\hat{\theta}$ & $\log \zeta$ \\
\hline Normal & $\begin{array}{c}-0.3607^{* * *} \\
(0.0239)\end{array}$ & 148.9589 & $\begin{array}{c}-0.3615^{* * *} \\
(0.0184)\end{array}$ & 149.5790 \\
\hline Plackett & $\begin{array}{c}0.3210^{* * *} \\
(0.0321)\end{array}$ & 152.4024 & $\begin{array}{c}0.3211 * * * \\
(0.0159)\end{array}$ & 152.4935 \\
\hline Rotated-Gumbel & $\begin{array}{l}1.1000 * * * \\
(0.0037)\end{array}$ & -121.9177 & $\begin{array}{l}1.1000 * * * \\
(0.0085)\end{array}$ & -120.9702 \\
\hline Student's t $\left(\rho, v^{-1}\right)$ & $\begin{array}{cc}-0.3697^{* * *} & 0.0910^{* * *} \\
(0.0231) & (0.0336)\end{array}$ & 160.9720 & $\begin{array}{cc}-0.3708^{* * *} & 0.0940 * * * \\
(0.0199) & (0.0275)\end{array}$ & 161.4015 \\
\hline
\end{tabular}

Note: this table presents the constant copula estimation results for the RUB-WTI pair. $\hat{\theta}$ is the estimated coefficient. $\log \zeta$ represents the $\log$-likelihood of each constant copula model. The values in parentheses are the standard error of the parameter. The values in bold indicate the highest log-likelihood values. ${ }^{* * *}$ indicates significance at $1 \%$ levels. 
Table 8. Constant copula parameter estimation (Indian Rupee-INR).

\begin{tabular}{|c|c|c|c|c|c|c|}
\hline \multirow{2}{*}{ Type } & \multicolumn{3}{|c|}{ Parametric } & \multicolumn{3}{|c|}{ Semi-Parametric } \\
\hline & \multicolumn{2}{|c|}{$\hat{\theta}$} & $\log \zeta$ & \multicolumn{2}{|c|}{$\hat{\theta}$} & $\log \zeta$ \\
\hline Normal & \multicolumn{2}{|c|}{$\begin{array}{c}-0.1166^{* * *} \\
(0.0196)\end{array}$} & 14.8911 & \multicolumn{2}{|c|}{$\begin{array}{c}-0.1157^{* * *} \\
(0.0197)\end{array}$} & 14.3927 \\
\hline Plackett & \multicolumn{2}{|c|}{$\begin{array}{c}0.7166^{* * *} \\
(0.0514)\end{array}$} & 12.7553 & \multicolumn{2}{|c|}{$\begin{array}{c}0.7228^{* * *} \\
(0.0452)\end{array}$} & 12.3592 \\
\hline Rotated-Gumbel & \multicolumn{2}{|c|}{$\begin{array}{c}1.1000^{* * *} \\
(0.0021)\end{array}$} & -54.1551 & \multicolumn{2}{|c|}{$\begin{array}{c}1.1000^{* * * *} \\
(0.0099)\end{array}$} & -56.5984 \\
\hline Student's t $\left(\rho, v^{-1}\right)$ & $\begin{array}{c}-0.1169 * * * \\
(0.0238)\end{array}$ & $\begin{array}{c}0.0505 * * \\
(0.0230)\end{array}$ & 17.4666 & $\begin{array}{c}-0.1154 * * * \\
(0.0248)\end{array}$ & $\begin{array}{l}0.0405^{* *} \\
(0.0230)\end{array}$ & 16.0603 \\
\hline
\end{tabular}

Note: this table presents the constant copula estimation results for the INR-WTI pair. $\hat{\theta}$ is the estimated coefficient. $\log \zeta$ represents the log-likelihood of each constant copula model. The values in parentheses are the standard error of the parameter. The values in bold indicate the highest log-likelihood values. ${ }^{* * *}$ indicates significance at $1 \%$ levels.

Table 9. Constant copula parameter estimation (Chinese Yuan-CNY).

\begin{tabular}{|c|c|c|c|c|}
\hline \multirow{2}{*}{ Type } & \multicolumn{2}{|l|}{ Parametric } & \multicolumn{2}{|c|}{ Semi-Parametric } \\
\hline & $\hat{\theta}$ & $\log \zeta$ & $\hat{\theta}$ & $\log \zeta$ \\
\hline Normal & $\begin{array}{c}-0.1560 * * * \\
(0.0222)\end{array}$ & 26.4584 & $\begin{array}{c}-0.1553^{* * *} \\
(0.0198)\end{array}$ & 26.0857 \\
\hline Plackett & $\begin{array}{l}0.6227^{* * *} \\
(0.0420)\end{array}$ & 26.2658 & $\begin{array}{c}0.6214 * * * \\
(0.0368)\end{array}$ & 26.2913 \\
\hline Rotated-Gumbel & $\begin{array}{l}1.1000^{* * *} \\
(0.0030)\end{array}$ & -67.8413 & $\begin{array}{l}1.1000^{* * *} \\
(0.0105)\end{array}$ & -65.9822 \\
\hline Student's t $\left(\rho, v^{-1}\right)$ & $\begin{array}{cc}-0.1562^{* * *} & 0.0493^{* *} \\
(0.0209) & (0.0216)\end{array}$ & 29.7568 & $\begin{array}{cc}-0.1591^{* * *} & 0.0515^{* *} \\
(0.0216) & (0.0228)\end{array}$ & 28.9640 \\
\hline
\end{tabular}

Note: this table presents the constant copula estimation results for the CNY-WTI pair. $\hat{\theta}$ is the estimated coefficient. $\log \zeta$ represents the log-likelihood of each constant copula model. The values in parentheses are the standard error of the parameter. The values in bold indicate the highest log-likelihood values. ${ }^{* *}$, and ${ }^{* * *}$ indicate significance at the $5 \%$, and $1 \%$ levels, respectively.

Table 10. Constant copula parameter estimation (South African Rand-ZAR).

\begin{tabular}{|c|c|c|c|c|}
\hline \multirow{2}{*}{ Type } & \multicolumn{2}{|l|}{ Parametric } & \multicolumn{2}{|c|}{ Semi-Parametric } \\
\hline & $\hat{\theta}$ & $\log \zeta$ & $\hat{\theta}$ & $\log \zeta$ \\
\hline Normal & $\begin{array}{l}-0.2587 * * * \\
(0.0197)\end{array}$ & 74.2223 & $\begin{array}{l}-0.2575^{* * *} \\
(0.0199)\end{array}$ & 73.2669 \\
\hline Plackett & $\begin{array}{c}0.4699^{* * *} \\
(0.0391)\end{array}$ & 66.3718 & $\begin{array}{c}0.4739^{* * *} \\
(0.0244)\end{array}$ & 65.4050 \\
\hline Rotated-Gumbel & $\begin{array}{l}1.1000^{* * *} \\
(0.0041)\end{array}$ & -93.5894 & $\begin{array}{l}1.1000^{* * *} \\
(0.0092)\end{array}$ & -94.3130 \\
\hline Student's $t\left(\rho, v^{-1}\right)$ & $\begin{array}{cc}-0.2605^{* * *} & 0.0416^{* *} \\
(0.0220) & (0.0205)\end{array}$ & 75.8064 & $\begin{array}{cc}-0.2576^{* * *} & 0.0421^{* *} \\
(0.0202) & (0.0224)\end{array}$ & 74.8820 \\
\hline
\end{tabular}

Note: this table presents the constant copula estimation results for the ZAR-WTI pair. $\hat{\theta}$ is the estimated coefficient. $\log \zeta$ represents the log-likelihood of each constant copula model. The values in parentheses are the standard error of the parameter. The values in bold indicate the highest log-likelihood values. ${ }^{* *}$, and ${ }^{* *}$ indicate significance at $5 \%$, and $1 \%$ levels, respectively. 
Table 11. Goodness-of-fit test for constant copula models.

\begin{tabular}{|c|c|c|c|c|}
\hline \multirow{2}{*}{ Type } & \multicolumn{2}{|c|}{ Parametric } & \multicolumn{2}{|c|}{ Semi-Parametric } \\
\hline & KS & CvM & KS & CvM \\
\hline & \multicolumn{4}{|c|}{ BRL } \\
\hline Normal & 0.63 & 0.38 & 0.18 & 0.03 \\
\hline Plackett & 0.67 & 0.31 & 0.00 & 0.00 \\
\hline Rotated-Gumbel & 0.00 & 0.00 & 0.00 & 0.00 \\
\hline \multirow[t]{2}{*}{ Student's t } & 0.70 & 0.36 & 0.16 & 0.03 \\
\hline & \multicolumn{4}{|c|}{ RUB } \\
\hline Normal & 0.50 & 1.00 & 0.13 & 0.13 \\
\hline Plackett & 0.62 & 1.00 & 0.10 & 0.10 \\
\hline Rotated-Gumbel & 0.00 & 0.00 & 0.00 & 0.00 \\
\hline \multirow[t]{2}{*}{ Student's t } & 0.55 & 1.00 & 0.29 & 0.28 \\
\hline & \multicolumn{4}{|c|}{ INR } \\
\hline Normal & 0.00 & 0.55 & 0.13 & 0.08 \\
\hline Plackett & 0.00 & 0.41 & 0.07 & 0.05 \\
\hline Rotated-Gumbel & 0.03 & 0.37 & 0.00 & 0.00 \\
\hline \multirow[t]{2}{*}{ Student's t } & 0.00 & 0.54 & 0.17 & 0.08 \\
\hline & \multicolumn{4}{|c|}{ CNY } \\
\hline Normal & 0.40 & 0.77 & 0.76 & 0.49 \\
\hline Plackett & 0.31 & 0.73 & 0.40 & 0.28 \\
\hline Rotated-Gumbel & 0.00 & 0.00 & 0.00 & 0.00 \\
\hline \multirow[t]{2}{*}{ Student's t } & 0.34 & 0.69 & 0.71 & 0.70 \\
\hline & \multicolumn{4}{|c|}{ ZAR } \\
\hline Normal & 0.16 & 0.57 & 0.30 & 0.29 \\
\hline Plackett & 0.39 & 0.49 & 0.05 & 0.03 \\
\hline Rotated-Gumbel & 0.00 & 0.00 & 0.00 & 0.00 \\
\hline Student's t & 0.43 & 0.64 & 0.40 & 0.26 \\
\hline
\end{tabular}

Note: this table presents the $p$-values of the goodness-of-fit tests for the constant copula models. Bold numbers indicate a rejection of the null hypothesis, which stares that the copula model provides the best fit to the data at the $1 \%$ level of significance. KS and CvM refer to the $p$-values from the Kolmogorov-Smirnov and Cramer-von Mises tests, respectively.

Table 12. Tail dependence coefficients of the Student's t copula model.

\begin{tabular}{ccc}
\hline \multirow{2}{*}{ Pair } & Parametric & Semi-Parametric \\
\cline { 2 - 3 } & $\hat{\lambda}^{L}\left(=\hat{\lambda}^{U}\right)$ & $\hat{\lambda}^{L}\left(=\hat{\lambda}^{U}\right)$ \\
\hline CNY-WTI & 0.4353 & 0.4337 \\
BRL-WTI & 0.4132 & 0.4136 \\
RUB-WTI & 0.3516 & 0.3504 \\
INR-WTI & 0.4477 & 0.4511 \\
ZAR-WTI & 0.4033 & 0.4041 \\
\hline
\end{tabular}

Note: this table presents the tail dependence coefficients estimated from the constant $S$ tudent's $t$ copula model.

\subsection{Time-Varying Copula Result}

Table 13 presents the estimated time-varying Student's $t$ copula model using the GAS model. For all pairs, the $\hat{\beta}$ estimate is highly significant and has a large value, except for the INR-WTI pair, indicating that the time-varying copula model parameters in this period have a great impact on the copula parameters of the following period.

Figure 2 presents the plot of the dynamic estimated parameters from time-varying Student's $t$ copula in the semi-parametric case. The red line indicates the average of the estimated time-varying parameters. As in the results from the constant copula models, all pairs reveal negative dependence 
structures in the following order: RUB-WTI, ZAR-WTI, BRL-WTI, CNY-WTI, and INR-WTI. This result is in line with our results from constant copula models.

Figure 3 reports the plot of the conditional tail dependence with time deviation in the semi-parametric case. For clarity, we used different scales for the y axis for the different pairs. In general, for all pairs, the tail dependence from the time-varying copula, which is less than 0.0025 , is much lower than that of the constant copula models (about 0.4).

Table 13. Time-varying copula parameter estimation.

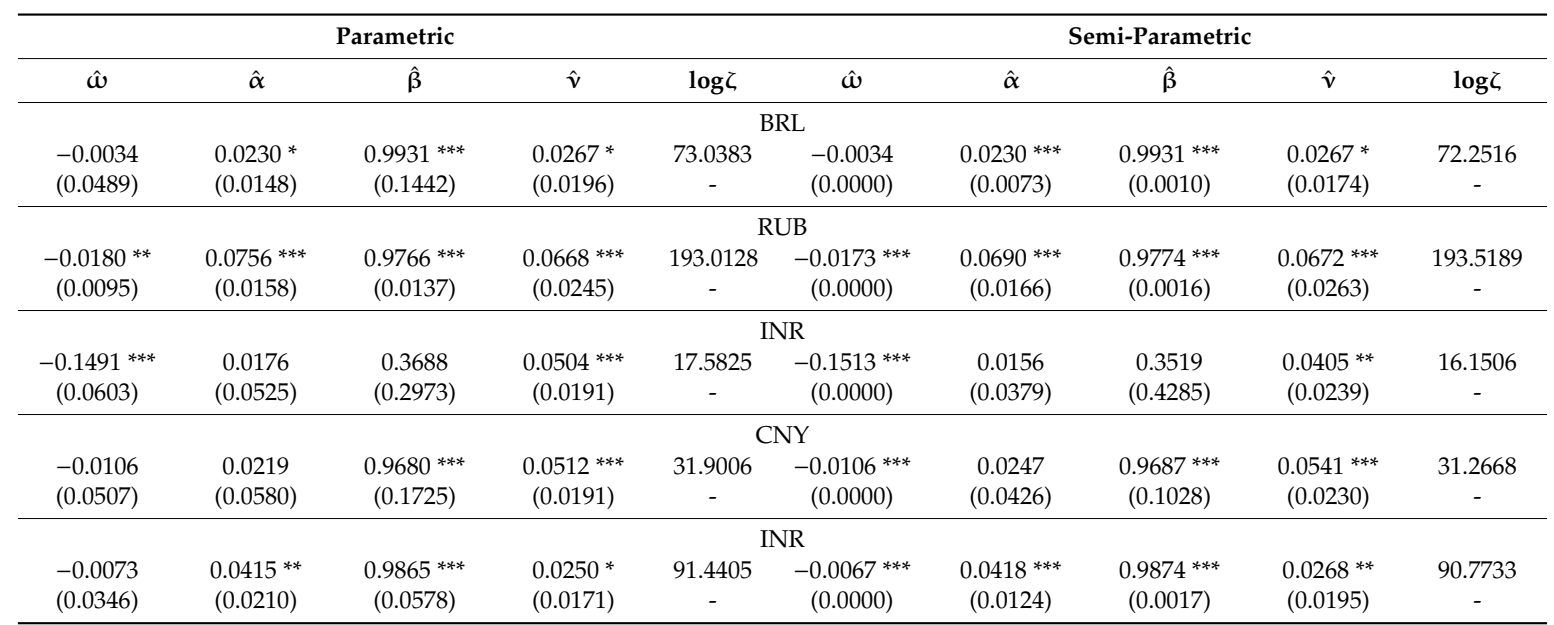

Note: this table presents the estimation results of the time-varying rotated-Gumbel and Student's $t$ copulas. $\hat{\omega}, \hat{\alpha}$, $\hat{\beta}$, and $\hat{v}$ are the estimated coefficients. $\log \zeta$ represents the log-likelihood of each time-varying copula model. The values in parentheses are the standard error of the parameter. ${ }^{*},{ }^{* *}$, and ${ }^{* * *}$ indicate significance at the $10 \%, 5 \%$, and $1 \%$ levels, respectively.

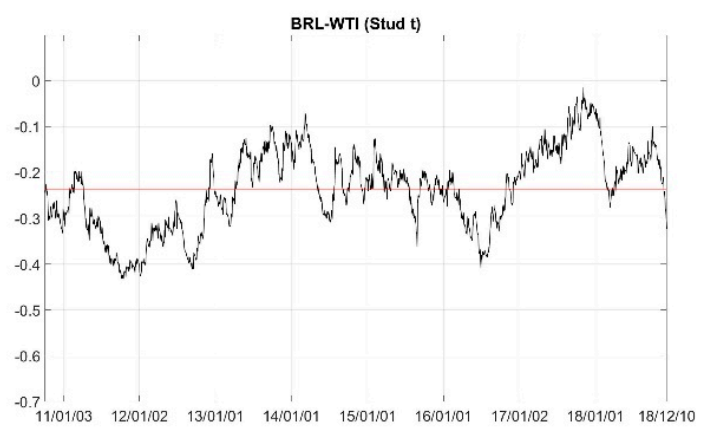

(a)

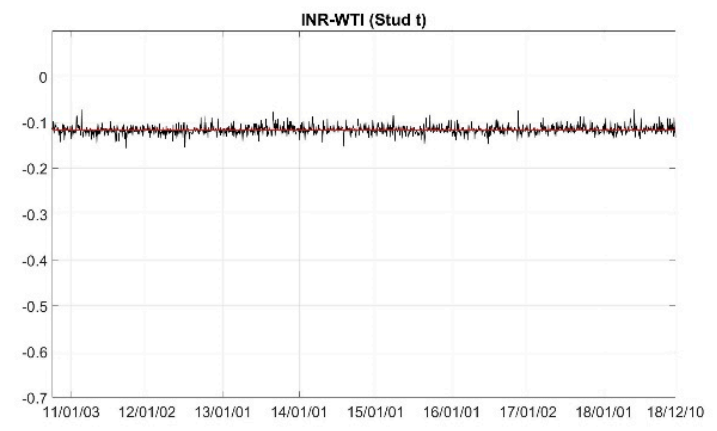

(c)

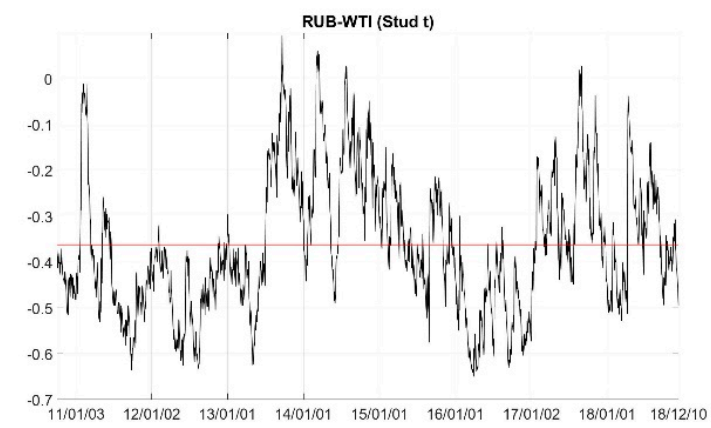

(b)

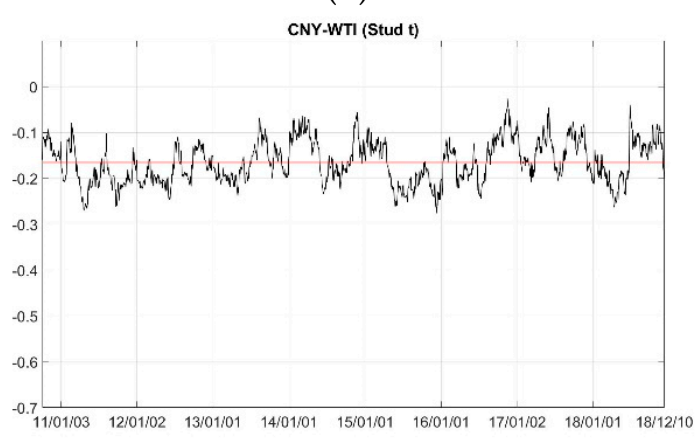

(d)

Figure 2. Cont. 


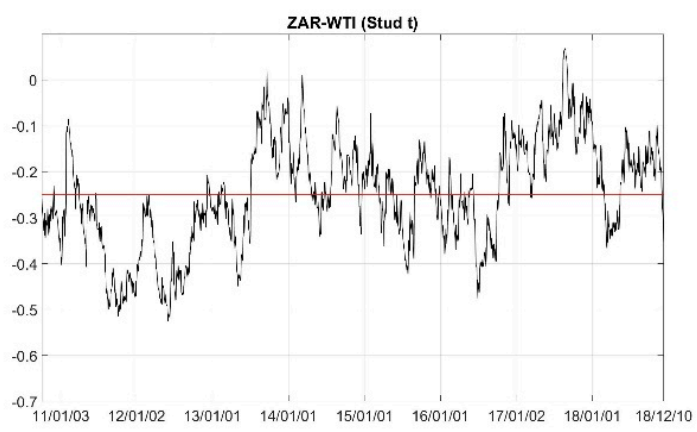

(e)

Figure 2. Dynamic parameters from the time-varying copula models. (a-e) refer to BRL-WTI, RUB-WTI, INR-WTI, CNY-WTI and ZAR-WTI pairs, respectively.

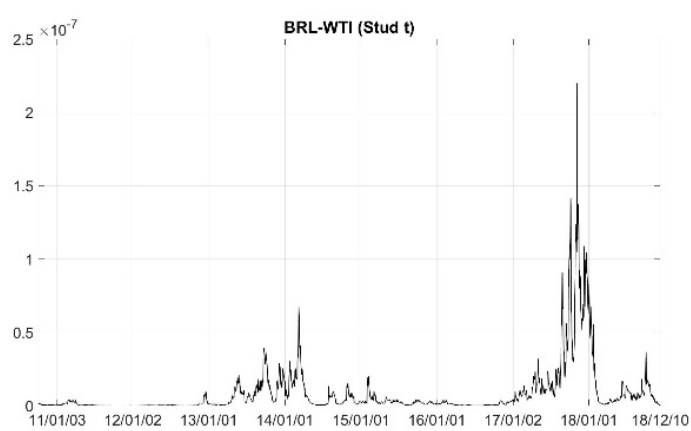

(a)

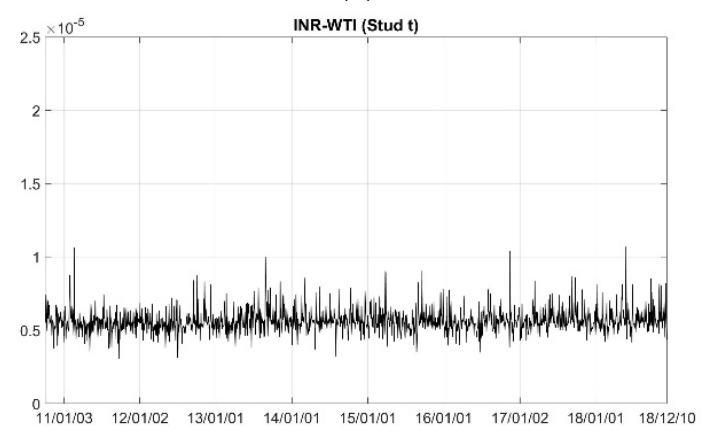

(c)

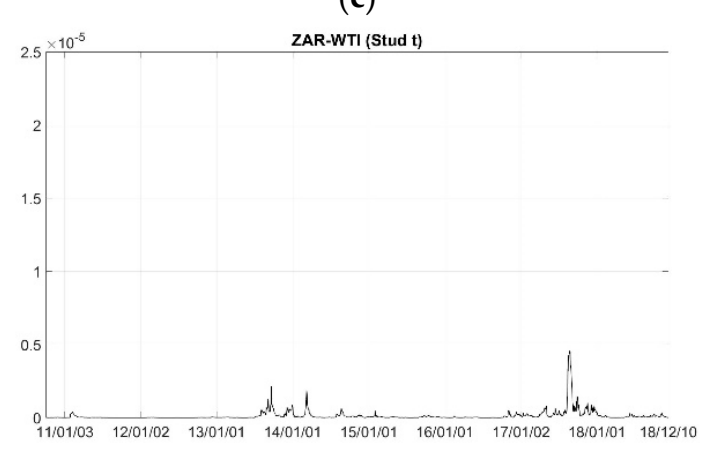

(e)

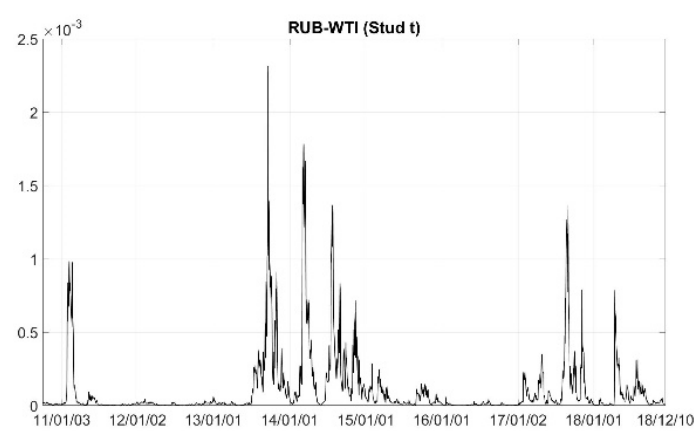

(b)

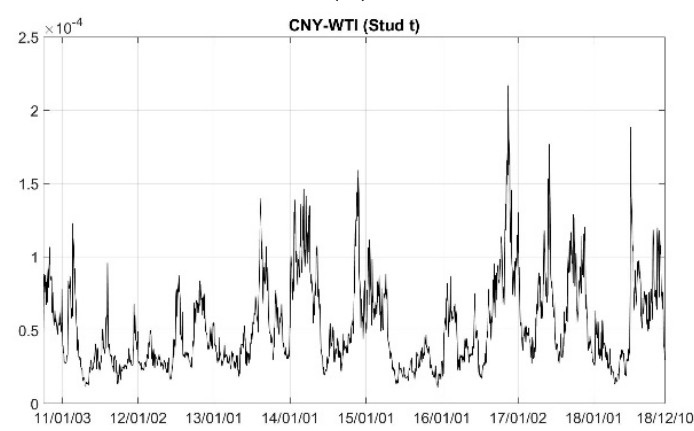

(d)

Figure 3. Conditional tail dependence from the time-varying copula models. (a-e) refer to pair of BRL-WTI, RUB-WTI, INR-WTI, CNY-WTI and ZAR-WTI, respectively.

Following Patton (2013), we tested the goodness-of-fit of the time-varying copula model by transforming the data through the Rosenblatt method, which is a multivariate version of the probability 
integral transformation proposed in Diebold et al. (1999) and developed further by Rémillard (2017). The transform uses the function:

$$
\begin{gathered}
\mathrm{V}_{1 \mathrm{t}}=\mathrm{U}_{1 \mathrm{t}} \forall \mathrm{t}, \\
\mathrm{V}_{2 \mathrm{t}}=\mathrm{C}_{2 \mid 1, \mathrm{t}}\left(\mathrm{U}_{2 \mathrm{t}} \mid \mathrm{U}_{1 \mathrm{t}} ; \theta\right) .
\end{gathered}
$$

Table 14 reports the $p$-values of the goodness-of-fit test. In the parametric case, the time-varying Student's t copula model is accepted with high $p$-values, except for INR-WTI pair with the KS test. In the semi-parametric case, the time-varying Student's t copula model is rejected for the BRL-WTI, INR-WTI, and ZAR-WTI pairs with the CvM test. Based on the results from the goodness-of-fit test, we consider that the constant copula model provides a better fit than the time-varying copula model for the INR-WTI pair.

Table 14. Goodness-of-fit test for the time-varying copula models.

\begin{tabular}{cccc}
\hline \multicolumn{2}{c}{ Parametric } & \multicolumn{2}{c}{ Semi-Parametric } \\
\hline KS & CvM & KS & CvM \\
\hline \multicolumn{4}{c}{ BRL } \\
0.9 & 0.83 & $\mathbf{0 . 0 0}$ & $\mathbf{0 . 0 0}$ \\
\hline \multicolumn{4}{c}{ RUB } \\
0.86 & 1.00 & 0.21 & 0.09 \\
\hline \multicolumn{5}{c}{ INR } \\
$\mathbf{0 . 0 0}$ & 0.55 & $\mathbf{0 . 0 0}$ & $\mathbf{0 . 0 0}$ \\
\hline \multicolumn{5}{c}{ CNY } \\
0.64 & 0.62 & 0.79 & 0.87 \\
\hline \multicolumn{5}{c}{ ZAR } \\
0.79 & 0.73 & 0.07 & $\mathbf{0 . 0 1}$
\end{tabular}

Note: this table presents the $p$-values of the goodness-of-fit test for the time-varying copula models. Bold numbers indicate a rejection of the null hypothesis, which states that the copula model provides the best fit to the data at the $1 \%$ level of significance. KS and CvM refer to the Kolmogorov-Smirnov and Cramer-von Mises tests, respectively.

\subsection{Value at Risk and Excepted Shortfall}

VaR and expected shortfall (ES) are statistics that quantify the risk of a portfolio. VaR measures the maximum expected loss with a confidence level, and ES measures the expected loss when the portfolio return is greater than the value of the VaR calculated with that confidence level. In this section, we treat the five exchange rate-oil price pairs (BRL-WTI, RUB-WTI, INR-WTI, CNY-WTI, and ZAR-WTI) as equally weighted portfolios, and then we calculate dynamic VaR and ES using a Monte Carlo simulation. The procedure has the following steps. Step 1: at each time $t$ ( $t$ is from 1 to $T$, where $\mathrm{T}$ is the length of the return series), generate 5000 random trials of uniform variables using the parameters estimated from the time-varying Student's t copula model. Step 2: transform the random uniform variables into standardized residuals, then conduct a series of new asset returns using the estimated parameters from the GARCH models. Step 3: use the portfolio weights ( $1 \%$ in this study) and the new asset returns to calculate the portfolio returns and then calculate the VaR and ES. Step 4: repeat steps $1-3 \mathrm{~T}$ times.

Figure 4 plots the results. We can see that the VaR begins at 3\%, decreases to $6 \%$ at the beginning of 2015 ( $9 \%$ for RUB-WTI), and from the middle of 2015 it decreases to reach approximately $8 \%$ by the beginning of 2016 for all pairs, due to the falling crude oil prices. Similarly, the ES also reaches a low value at that period. 


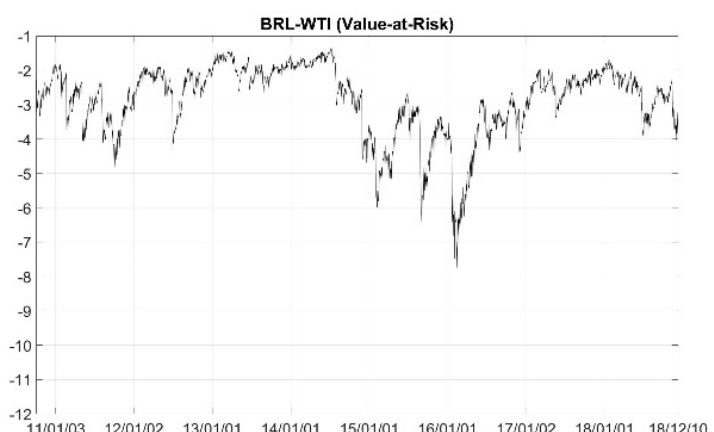

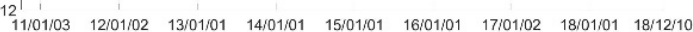
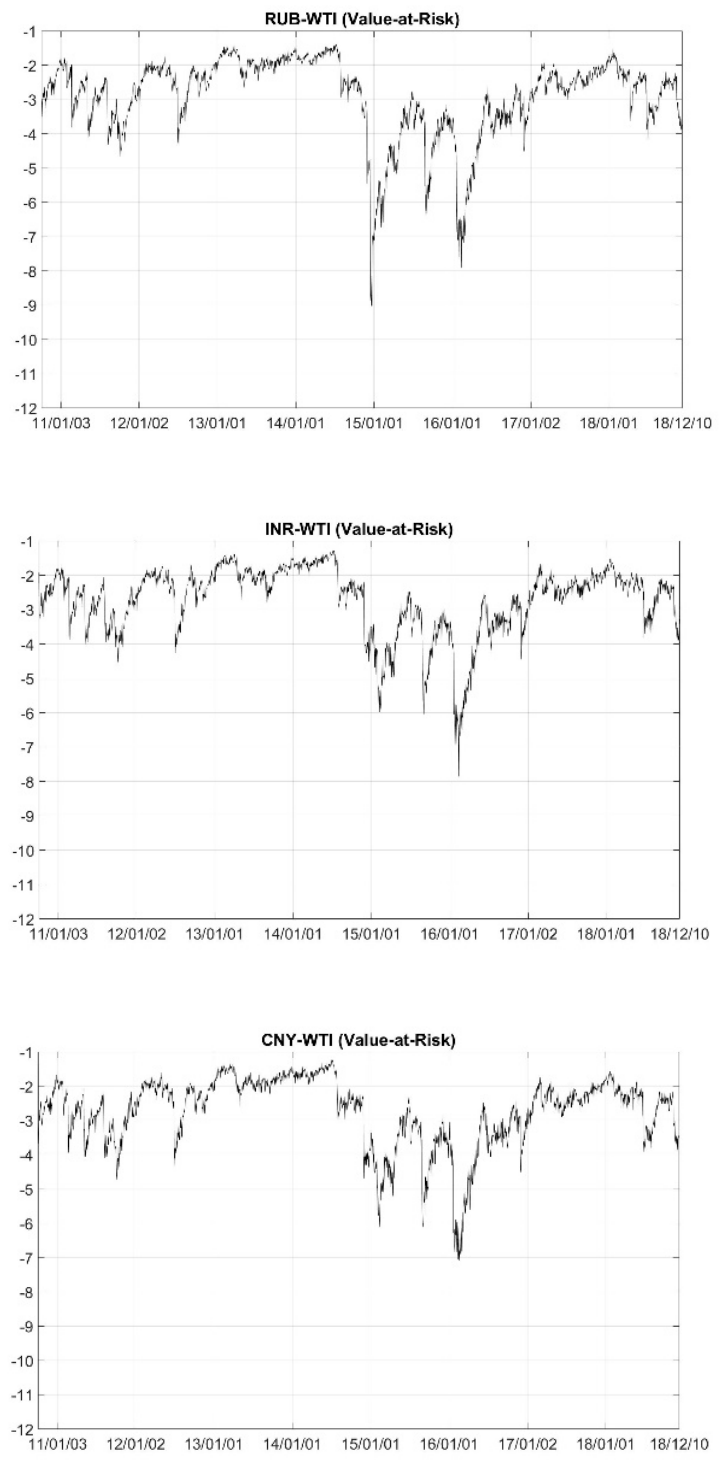

(a)

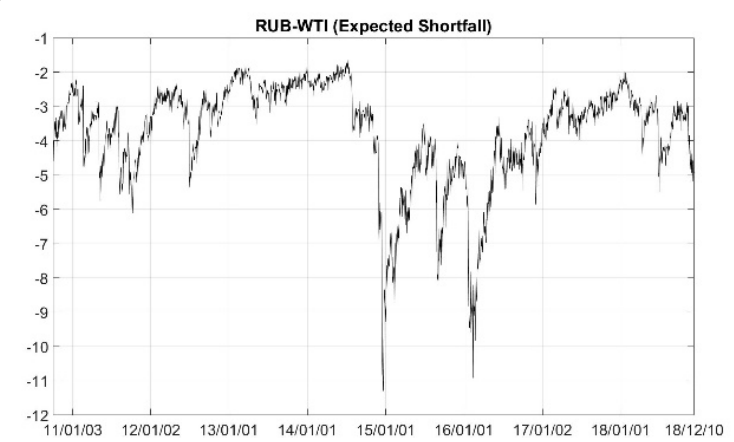

(b)

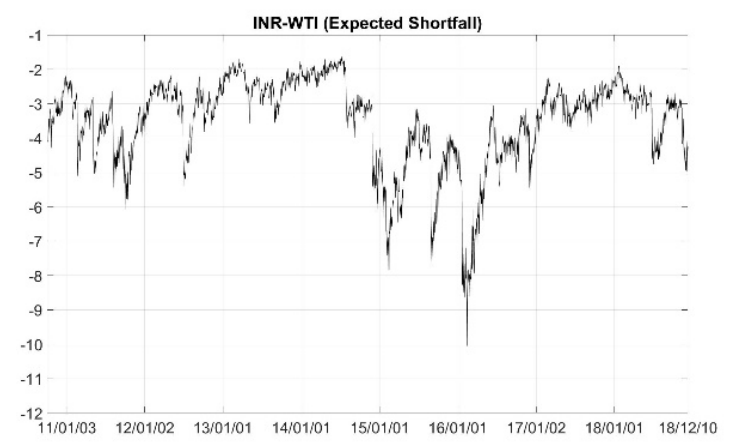

(c)

BRL-WTI (Expected Shortfall)
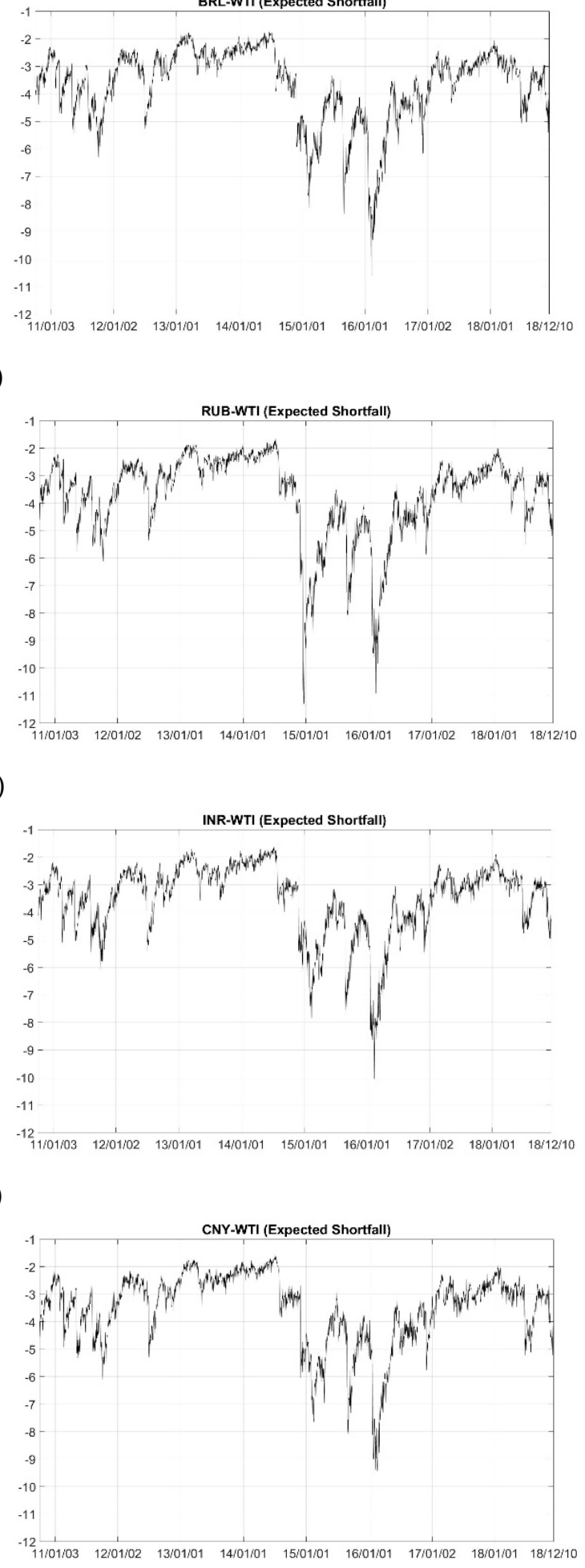

(d)

Figure 4. Cont. 

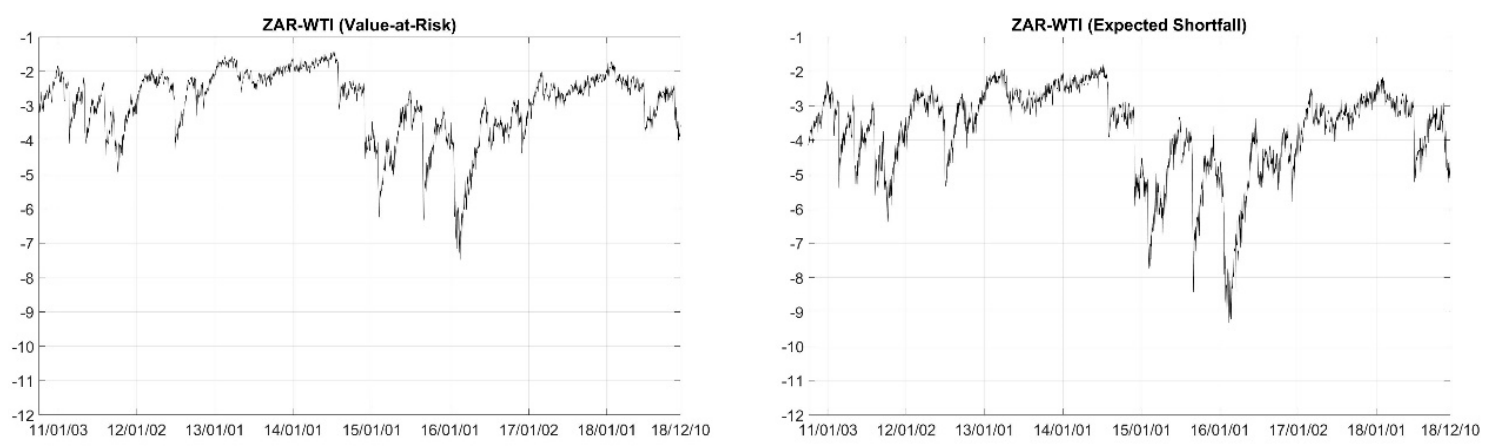

(e)

Figure 4. Conditional 1\% Value at Risk (left panel) and Expected Shortfall (right panel) for an equal-weighted portfolio based on the Student's t copula model. (a-e) refer to BRL-WTI, RUB-WTI, INR-WTI, CNY-WTI and ZAR-WTI pairs, respectively.

\section{Conclusions}

This study examined both the constant and dynamic dependencies between crude oil prices (WTI) and exchange rates for the BRICS countries, which includes oil-exporting and oil-importing economies, from 4 October 2010 to 11 December 2018. We employed constant and time-varying copula-GARCH-based models to capture the nonlinear, asymmetric, and tail dependence between the two variables.

The empirical results showed, first, that a significant dependence existed in all exchange rate-oil price pairs, and the dependence is negative, which means that oil serves as a hedge against rising inflation in BRICS countries. For example, when one currency appreciates, consumers from that country will find the oil price less expensive and then increase their demand for oil, which will lead to a rise in the oil price. Second, in both the constant and time-varying copula models, the RUB-WTI pair has the strongest dependence, possibly because Russia is a large oil producer and has a high share of global oil exports, making Russia itself more dependent on oil. Third, from the goodness-of-fit test results, the Student's t copula model has the best performance among all the constant copula models considered, while for the time-varying copula models, it was rejected for the BRL-WTI, INR-WTI, and ZAR-WTI pairs. We also measured risk management by treating the five exchange rate-oil price pairs as portfolios and calculating the dynamic values of VaR and ES. Both reached very low values for all pairs when the oil price experienced a sharp decrease.

The results of this paper offer us several suggestions. First, the significant correlation between oil price and exchange rate indicates that enterprises and governments in BRICS countries, when the oil price fluctuates, should pay attention to the exchange rate risk. Second, the negative relationship between oil price and exchange rate shows that the oil could be a hedge against inflation in BRICS countries, which is useful for foreign investors to manage exchange rate risk.

However, in this paper, we only considered bivariate copula models. For the future extension of this research, we will focus on a high-dimensional copula model, which could provide a more flexible analysis. 
Author Contributions: S.H. conceived and designed the experiments; Y.H. performed the experiments, analyzed the data, and contributed reagents/materials/analysis tools; Y.H. and S.H. wrote the paper.

Funding: This work was supported by JSPS KAKENHI Grant Number (A) 17H00983.

Acknowledgments: We are grateful to the editor and three anonymous referees for many helpful comments and suggestions.

Conflicts of Interest: The authors declare no conflict of interest.

\section{Appendix A. ARMA-GARCH Results}

Table A1 summarizes the results of ARMA-GARCH models. We first use ARMA models to estimate the return series, and then use GARCH model to estimate the residuals from the ARMA models to obtain the standard residuals. We chose the ARMA model lags using the AIC criterion. All returns series are modeled by standard GARCH model at first, but the standard residuals in RUB and ZAR returns, could not pass the Ljung-Box test and Lagrange Multiplier test, which means the GARCH model is not fitted well in these returns. Hence, we chose GJR-GARCH model in fitting RUB and ZAR return data. As mentioned in the main text, each GARCH model tests the hypothesis that the error item follows a skewed $t$ distribution. Almost all estimated parameters from the GARCH models are significant at the $1 \%$ level. Persistence coefficients $(\alpha+\beta$ in GARCH model, $\alpha+\beta+\gamma / 2$ in GJR-GARCH model) in all models are very close to 1 , which reveal the existence of volatility clustering. This appears show that when the volatility is high, it is likely to remain high and vice versa when the volatility is low. This consequence is also in line with previous research.

Table A2 provides the results of the Ljung-Box test of the standardized residuals and squared standard residuals (up to 20 lags), as well as the Lagrange Multiplier test of the standardized residuals. All values are insignificant, meaning that the standardized residuals obtained from the GARCH model have no serial correlation and autoregressive conditional heteroscedasticity. 
Table A1. Marginal distribution parameter estimation.

\begin{tabular}{|c|c|c|c|c|c|c|c|c|c|c|c|c|c|}
\hline Variable & $\varphi$ & AR (1) & AR (2) & AR (3) & MA (1) & MA (2) & $\omega$ & $\alpha$ & B & $\gamma$ & $\lambda$ & $v$ & Persistence \\
\hline BRL & $\begin{array}{c}0.0138 \\
(0.0153)\end{array}$ & - & - & - & - & - & $\begin{array}{c}0.0068^{* *} \\
(0.0031)\end{array}$ & $\begin{array}{c}0.0882^{* * *} \\
(0.0164)\end{array}$ & $\begin{array}{c}0.9105^{* * *} \\
(0.0151)\end{array}$ & - & $\begin{array}{c}1.0000^{* * *} \\
(0.0291)\end{array}$ & $\begin{array}{c}5.5195^{* * * *} \\
(0.6392)\end{array}$ & 0.9988 \\
\hline RUB & $\begin{array}{c}0.0239 \\
(0.0153)\end{array}$ & $\begin{array}{c}0.0574^{* * *} \\
(0.0219)\end{array}$ & - & - & - & - & $\begin{array}{c}0.0080^{* * *} \\
(0.0026)\end{array}$ & $\begin{array}{c}0.1194^{* * *} \\
(0.0222)\end{array}$ & $\begin{array}{c}0.9163 \text { *** } \\
(0.0166)\end{array}$ & $\begin{array}{c}-0.0891 * * * \\
(0.0190)\end{array}$ & $\begin{array}{c}1.0000^{* * * *} \\
(0.0304)\end{array}$ & $\begin{array}{c}6.6418^{* * *} \\
(0.9238)\end{array}$ & 0.9911 \\
\hline INR & $\begin{array}{l}-0.0122 \\
(0.0074)\end{array}$ & $\begin{array}{c}0.5749^{* * *} \\
(0.0390)\end{array}$ & $\begin{array}{c}-0.9716^{* * *} \\
(0.0137)\end{array}$ & $\begin{array}{c}0.0127 \\
(0.0271)\end{array}$ & $\begin{array}{c}-0.5719^{* * *} \\
(0.0251)\end{array}$ & $\begin{array}{c}0.9567^{* * *} \\
(0.0049)\end{array}$ & $\begin{array}{c}0.0032 * * \\
(0.0014)\end{array}$ & $\begin{array}{c}0.1096^{* * *} \\
(0.0236)\end{array}$ & $\begin{array}{c}0.8891^{* * *} \\
(0.0236)\end{array}$ & - & $\begin{array}{c}0.9000^{* * * *} \\
(0.0229)\end{array}$ & $\begin{array}{c}4.1632 * * * \\
(0.4281)\end{array}$ & 0.9987 \\
\hline CNY & $\begin{array}{c}-0.0069^{* * *} \\
(0.0026)\end{array}$ & $\begin{array}{c}0.4704^{* * *} \\
(0.1816)\end{array}$ & $\begin{array}{c}-0.0623^{* * *} \\
(0.0212)\end{array}$ & - & $\begin{array}{c}-0.4603^{* *} \\
(0.1806)\end{array}$ & - & $\begin{array}{c}0.0004^{* * *} \\
(0.0001)\end{array}$ & $\begin{array}{c}0.1077^{* * *} \\
(0.0179)\end{array}$ & $\begin{array}{c}0.8913^{* * *} \\
(0.0164)\end{array}$ & - & $\begin{array}{c}0.9982^{* * * *} \\
(0.0281)\end{array}$ & $\begin{array}{c}4.0425^{* * *} \\
(0.3212)\end{array}$ & 0.9990 \\
\hline ZAR & $\begin{array}{c}0.0136 \\
(0.0203)\end{array}$ & $\begin{array}{c}0.0173 \\
(0.0218)\end{array}$ & - & - & - & - & $\begin{array}{c}0.0068^{* * *} \\
(0.0024)\end{array}$ & $\begin{array}{c}0.0496^{* * *} \\
(0.0068)\end{array}$ & $\begin{array}{c}0.9636^{* * *} \\
(0.0028)\end{array}$ & $\begin{array}{c}-0.0423 * * * \\
(0.0106)\end{array}$ & $\begin{array}{c}0.9000^{* * * *} \\
(0.0267)\end{array}$ & $\begin{array}{c}8.3036^{* * *} \\
(1.3302)\end{array}$ & 0.9921 \\
\hline WTI & $\begin{array}{l}-0.0049 \\
(0.0339)\end{array}$ & - & - & - & $\begin{array}{c}-0.0390 * \\
(0.0213)\end{array}$ & - & $\begin{array}{c}0.0253^{* *} \\
(0.0119)\end{array}$ & $\begin{array}{c}0.0551^{* * *} \\
(0.0109)\end{array}$ & $\begin{array}{c}0.9408^{* * *} \\
(0.0115)\end{array}$ & - & $\begin{array}{c}0.9121 * * * \\
(0.0262)\end{array}$ & $\begin{array}{c}5.7172 * * * \\
(0.7056)\end{array}$ & 0.9959 \\
\hline
\end{tabular}

Note: this table presents the estimated parameters from the marginal distribution. $\varphi$, AR (p), and MA (q) are the estimated parameters from the ARMA (p, q) model. $\omega, \alpha, \beta(, \gamma)$ are the estimated parameters from the GARCH (GJR-GARCH) model. $\lambda, v$ are the estimated parameters from skewed t model for the distribution of the error term. The persistence is calculated by $\alpha+\beta$ in GARCH model and by $\alpha+\beta+\gamma / 2$ in GJR-GARCH model. The values in parenthesis represent the standard errors of each parameter. ${ }^{*}, * *$, and ${ }^{* * *}$ indicate significance at the $10 \%$, $5 \%$, and $1 \%$ levels, respectively. 
Table A2. Ljung-Box test and Lagrange Multiplier test.

\begin{tabular}{cccc}
\hline Variable & $\mathbf{Q} \mathbf{( 2 0 )}$ & $\mathbf{Q}^{\wedge} \mathbf{2}(\mathbf{2 0 )}$ & ARCH (20) \\
\hline CNY & 15.3600 & 0.1734 & 0.1692 \\
$p$-value & 0.7554 & 1.0000 & 1.0000 \\
BRL & 15.9640 & 6.3681 & 6.4523 \\
$p$-value & 0.7189 & 0.9983 & 0.9981 \\
RUB & 32.7250 & 26.9020 & 26.7650 \\
$p$-value & 0.0362 & 0.1380 & 0.1420 \\
INR & 23.5130 & 23.5590 & 23.3340 \\
$p$-value & 0.2643 & 0.2622 & 0.2727 \\
ZAR & 20.7420 & 24.8260 & 23.7330 \\
$p$-value & 0.4125 & 0.2082 & 0.2543 \\
WTI & 13.4890 & 10.3330 & 10.2270 \\
$p$-value & 0.8554 & 0.9617 & 0.9639 \\
\hline
\end{tabular}

Note: this table presents the empirical statistics and $p$-values of the Ljung-Box test and Lagrange Multiplier test of the standard residuals from the GARCH model. Q (20) and Q^2 (20) are the Ljung-Box test statistics for serial correlation of order 20 for the standardized residuals and squared standardized residuals from the GARCH model. $\mathrm{ARCH}(20)$ is the Lagrange Multiplier test statistics for autoregressive conditional heteroscedasticity.

\section{Appendix B. Robustness Analysis}

To examine the robustness of our results, we used the Brent crude oil price to analyze five currency-oil price pairs: BRL-BRENT, RUB-BRENT, INR-BRENT, CNY-BRENT, and ZAR-BRENT. We modeled the dependence structure for exchange rates and oil prices.

We summarize the rank correlation and linear correlation results, and the tail dependence from the constant Student's t copula model in Tables A3 and A4, respectively. We plot the estimated dynamic parameters and tail dependences in Figures A1 and A2, respectively, and illustrate the results for the dynamic VaR and ES Figure A3.

All results are consistent with those for the exchange rate-WTI pairs, which confirm the suitability of our proposed approach to capture the dependence structure between exchange rates and crude oil prices.

Table A3. Rank correlation and linear correlation.

\begin{tabular}{cccc}
\hline Pair & Kendall's $\tau$ & Spearman's $\rho$ & Pearson \\
\hline CHY-BRENT & $-0.0884^{* * *}$ & $-0.1318^{* * *}$ & $-0.1124^{* * *}$ \\
BRL-BRENT & $-0.1573^{* * *}$ & $-0.2329^{* * *}$ & $-0.2219^{* * *}$ \\
RUB-BRENT & $-0.2853^{* * *}$ & $-0.4104^{* * *}$ & $-0.3914^{* * *}$ \\
INR-BRENT & $-0.0718^{* * *}$ & $-0.1075^{* * *}$ & $-0.1181^{* * *}$ \\
ZAR-BRENT & $-0.1547^{* * *}$ & $-0.2282^{* * *}$ & $-0.2343^{* * *}$ \\
\hline
\end{tabular}

Note: this table presents the Kendall's $\tau$ correlation coefficient, Spearman's $\rho$ correlation coefficient, and Pearson correlation coefficient for the exchange rate-BRENT oil price pairs. ${ }^{* * *}$ indicates significance at $1 \%$ level.

Table A4. Tail dependence coefficients of the Student's t copula model.

\begin{tabular}{ccc}
\hline Pair & Parametric & Semi-Parametric \\
\hline & $\hat{\lambda}^{L}\left(=\hat{\lambda}^{U}\right)$ & $\hat{\lambda}^{L}\left(=\hat{\lambda}^{U}\right)$ \\
\hline CNY-BRENT & 0.4064 & 0.4064 \\
BRL-BRENT & 0.4194 & 0.4194 \\
RUB-BRENT & 0.3214 & 0.3214 \\
INR-BRENT & 0.4494 & 0.4494 \\
ZAR-BRENT & 0.4151 & 0.4151 \\
\hline
\end{tabular}

Note: this table presents the tail dependence coefficients estimated from the constant Student's $t$ copula model for the exchange rate-BRENT oil price pairs. 


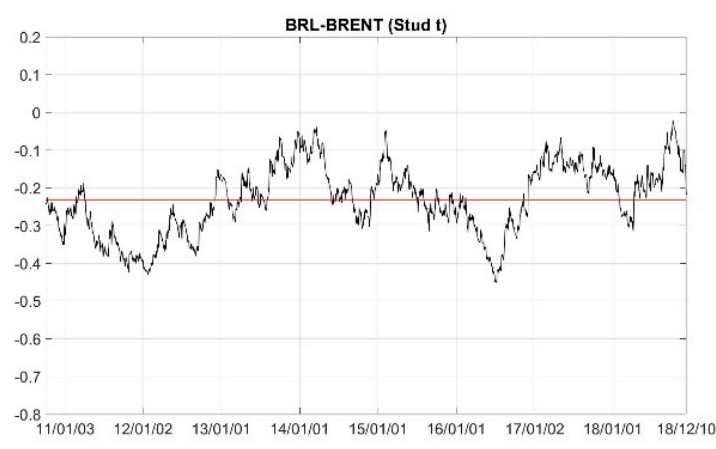

(a)

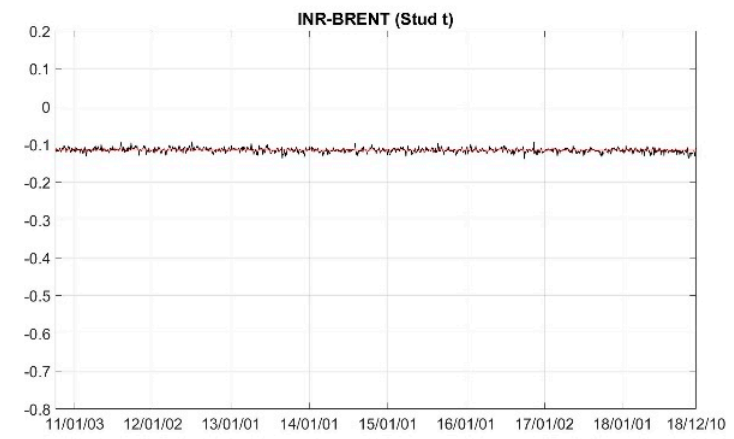

(c)

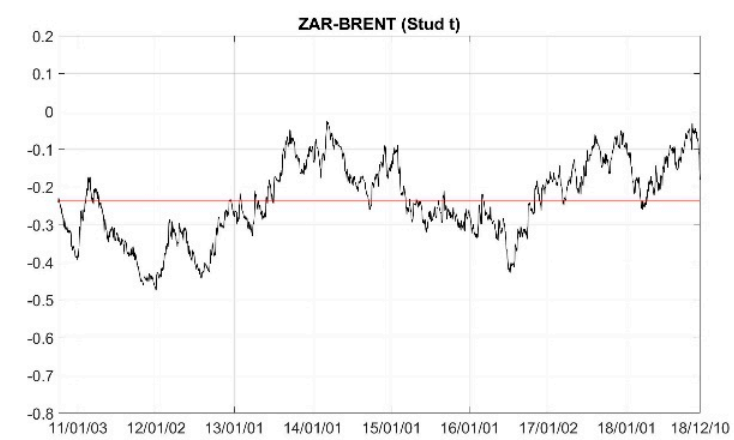

(e)

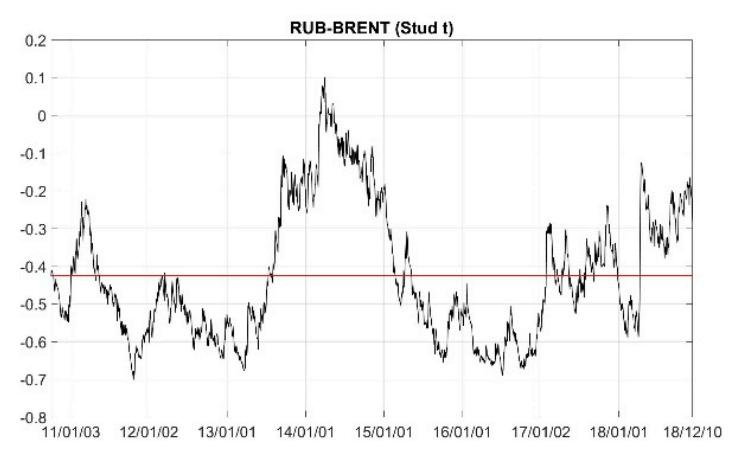

(b)

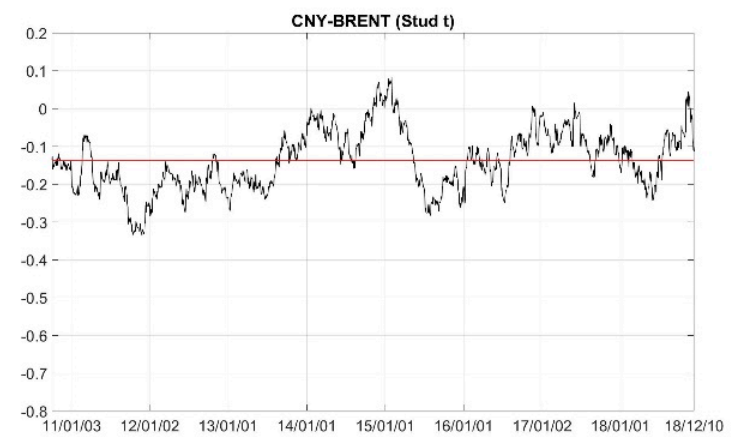

(d)

Figure A1. Dynamic parameters from the time-varying copula models. (a-e) refer to BRL-BRENT, RUB-BRENT, INR-BRENT, CNY-BRENT and ZAR-BRENT pairs, respectively. 


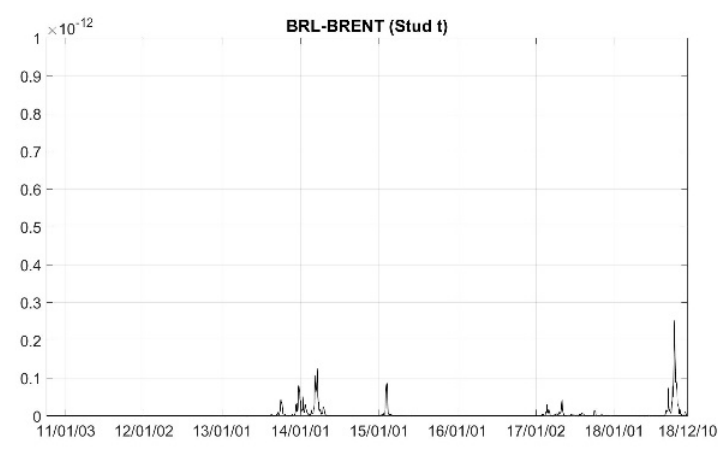

(a)

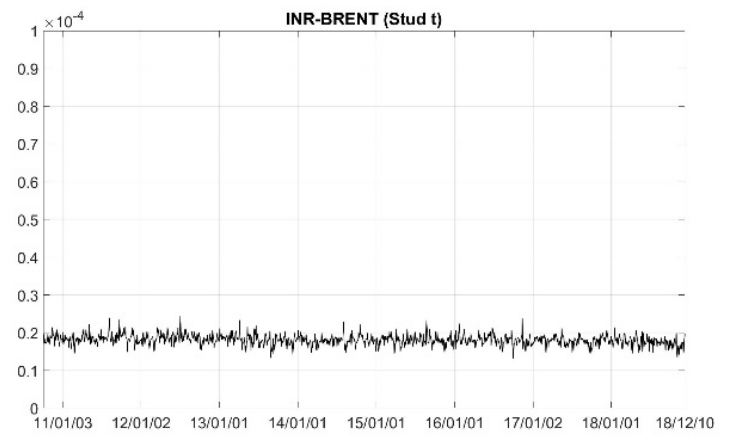

(c)

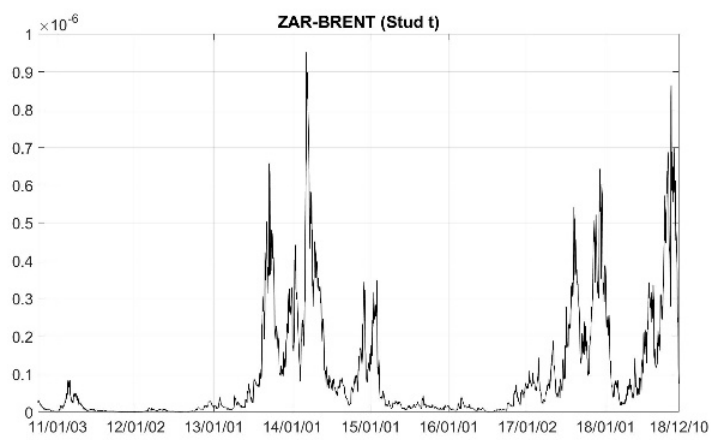

(e)

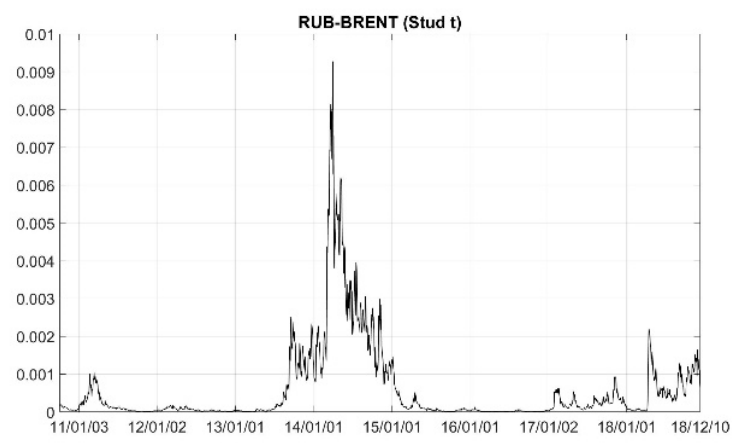

(b)

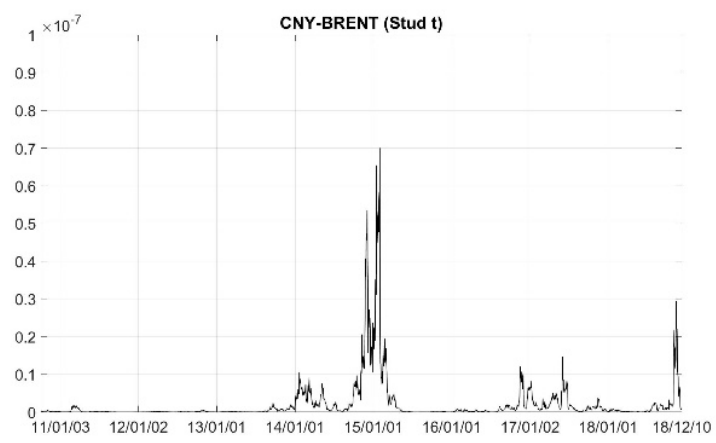

(d)

Figure A2. Conditional tail dependence from the time-varying copula models. (a-e) refer to pair of BRL-BRENT, RUB-BRENT, INR-BRENT, CNY-BRENT and ZAR-BRENT pairs, respectively.

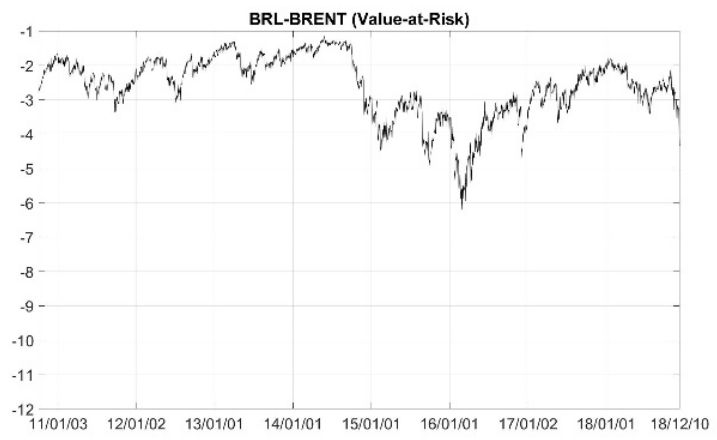

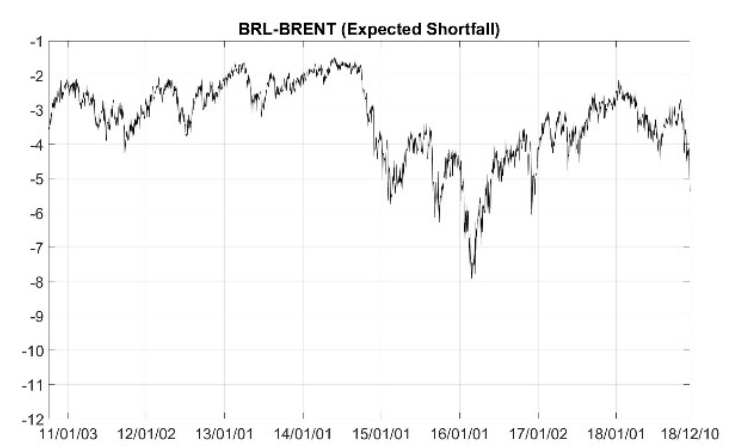

(a)

Figure A3. Cont. 

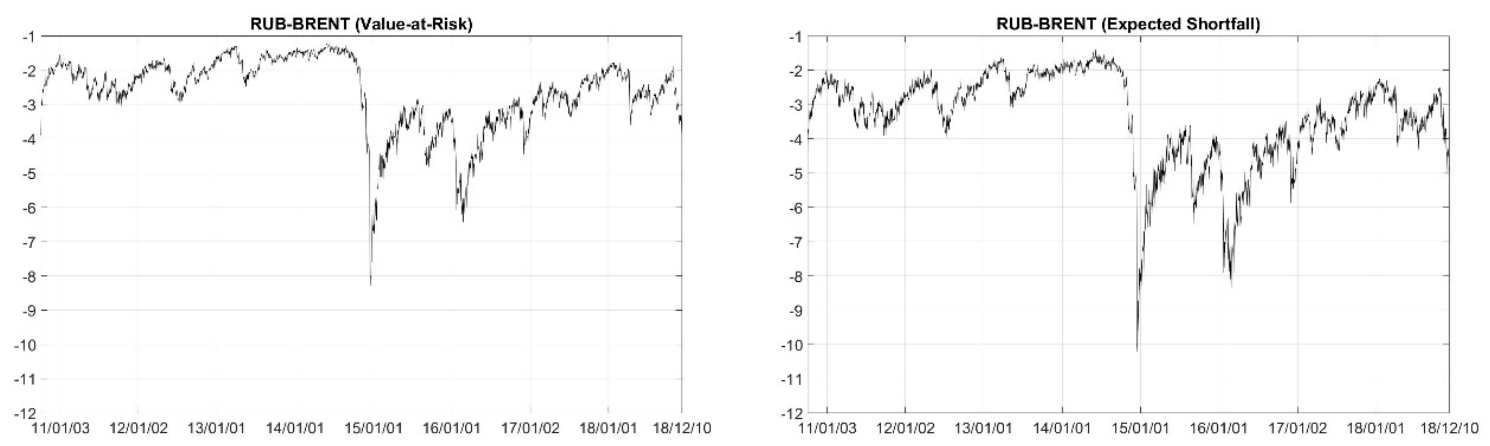

(b)
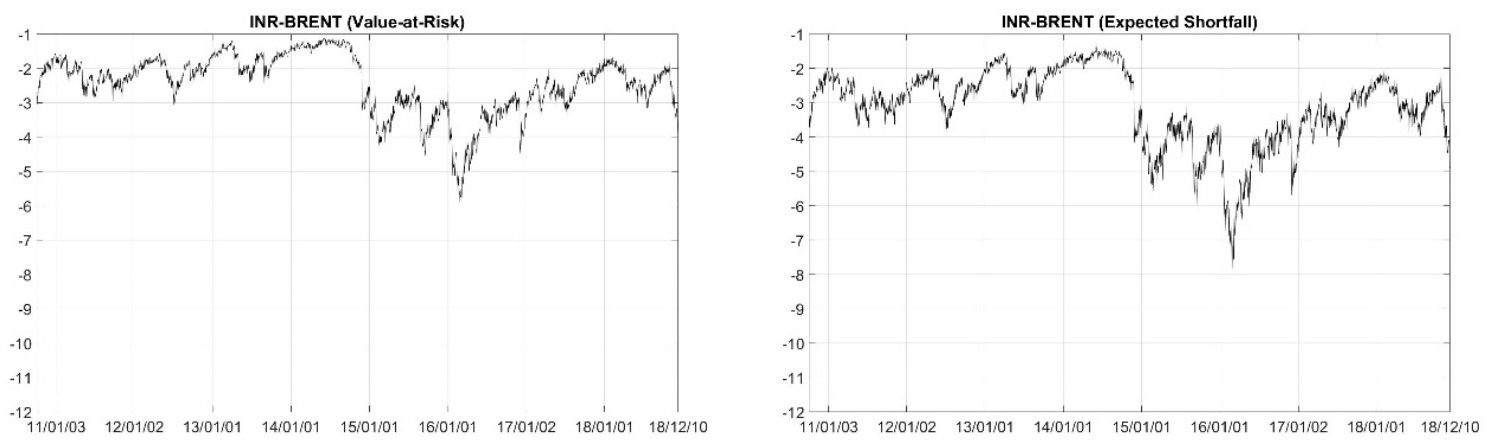

(c)
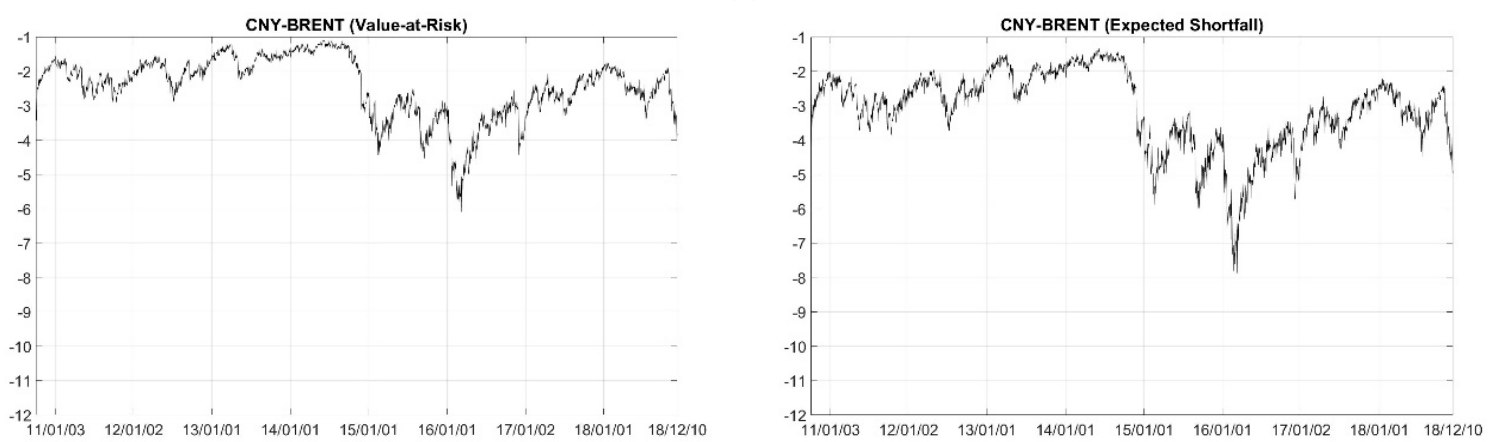

(d)
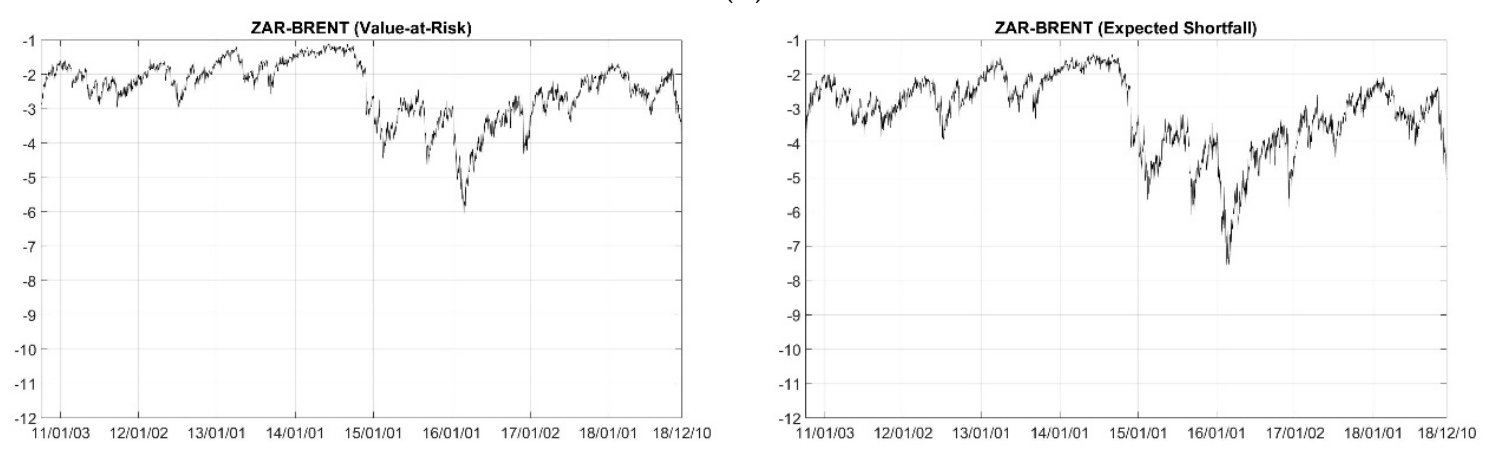

(e)

Figure A3. Conditional 1\% Value-at-Risk (left panel) and Expected Shortfall (right panel) for an equal-weighted portfolio based on the Student's t copula model. (a-e) refer to pair of BRL-BRENT, RUB-BRENT, INR-BRENT, CNY-BRENT and ZAR-BRENT pairs, respectively. 


\section{References}

Akram, Q. Farooq. 2009. Commodity prices, interest rates and the dollar. Energy Economics 31: 838-51. [CrossRef] Aloui, Riadh, Mohamed Safouane Ben Aïssa, and Duc Khuong Nguyen. 2013. Conditional dependence structure between oil prices and exchange rates: A copula-GARCH approach. Journal of International Money and Finance 32: 719-38. [CrossRef]

Bai, Jushan, and Pierre Perron. 1998. Estimating and testing linear models with multiple structural changes. Econometrica 66: 47-78. [CrossRef]

Bai, Jushan, and Pierre Perron. 2003. Computation and analysis of multiple structural change models. Journal of Applied Econometrics 18: 1-22. [CrossRef]

Basher, Syed Abul, Alfred A. Haug, and Perry Sadorsky. 2012. Oil prices, exchange rates and emerging stock markets. Energy Economics 34: 227-40. [CrossRef]

Beckmann, Joscha, Robert Czudaj, and Vipin Arora. 2017. The Relationship between Oil Prices and Exchange Rates: Theory and Evidence. Washington: Financial and physical Oil Market Linkages Workshop.

Bénassy-Quéré, Agnès, Valérie Mignon, and Alexis Penot. 2007. China and the relationship between the oil price and the dollar. Energy Policy 35: 5795-805. [CrossRef]

Blokhina, Tatiana K., Okasana A. Karpenko, and Andrey V. Guirinskiy. 2016. The relationship between oil prices and exchange rate in Russia. International Journal of Energy Economics and Policy 6: 721-26.

Bodenstein, Martin, Christopher J. Erceg, and Luca Guerrieri. 2011. Oil shock and external adjustment. Journal of International Economics 83: 168-84. [CrossRef]

Chen, Shiu-Sheng, and Hung-Chyn Chen. 2007. Oil prices and real exchange rates. Energy Economics 29: 390-404. [CrossRef]

Creal, Drew, Siem Jan Koopman, and André Lucas. 2013. Generalized autoregressive score models with applications. Journal of Applied Econometrics 28: 777-95. [CrossRef]

Diebold, Francis X., Jinyong Hahn, and Anthony S. Tay. 1999. Multivariate density forecast evaluation and calibration in financial risk management: High-frequency returns on foreign exchange. Review of Economics and Statistics 81: 661-73. [CrossRef]

Ding, Liang, and Minh Vo. 2012. Exchange rates and oil prices: A multivariate stochastic volatility analysis. The Quarterly Review of Economics and Finance 52: 15-37. [CrossRef]

Genest, Christian, Bruno Rémillard, and David Beaudoin. 2009. Goodness-of-fit tests for copulas: A review and a power study. Insurance: Mathematics and Economics 44: 199-213. [CrossRef]

Ghosh, Sajal. 2011. Examining crude oil price-Exchange rate nexus for India during the period of extreme oil price volatility. Applied Energy 88: 1886-89. [CrossRef]

Gisser, Micha, and Thomas H. Goodwin. 1986. Crude oil and the macroeconomy: Tests of some popular notions: Note. Journal of Monety, Credit and Banking 18: 95-103. [CrossRef]

Habib, Maurizio Michael, Sascha Bützer, and Livio Stracca. 2016. Global Exchange Rate Configurations: Do Oil Shocks Matter? IMF Economic Review 64: 443-70. [CrossRef]

Hamilton, James D. 1983. Oil and the Macroeconomy since World War II. Journal of Political Economy 91: 228-48. [CrossRef]

Hansen, Bruce E. 1994. Autoregressive Conditional Density Estimation. International Economic Review 35: 705-30. [CrossRef]

Ji, Qiang, Bing-Yue Liu, and Ying Fan. 2019. Risk dependence of CoVaR and structural change between oil prices and exchange rates: A time-varying copula model. Energy Economics 77: 80-92. [CrossRef]

Kin, Sibanda, and Mlambo Courage. 2014. The impact of oil prices on the exchange rate in South Africa. Journal of Economics 5: 193-99. [CrossRef]

Mork, Knut Anton. 1989. Oil and the macroeconomy when prices go up and down: an extension of Hamilton's results. Journal of Political Economy 97: 740-44. [CrossRef]

Narayan, Seema. 2013. Foreign exchange markets and oil prices in Asia. Journal of Asian Economics 28: 41-50. [CrossRef]

Narayan, Paresh Kumar, Seema Narayan, and Arti Prasad. 2008. Understanding the oil price-exchange rate nexus for the Fiji Islands. Energy Economics 30: 2686-96. [CrossRef]

Nelsen, Roger B. 2006. An Introduction to Copulas. New York: Springer, pp. 89-121. 
Nelson, Daniel B. 1991. Conditional Heteroskedasticity in Asset Returns: A New Approach. Econometrica 59: 347-70. [CrossRef]

Patton, Andrew J. 2006. Modelling asymmetric exchange rate dependence. International Economic Review 47: 527-56. [CrossRef]

Patton, Andrew J. 2013. Copula methods for forecasting multivariate time series. In Handbook of Economic Forecasting, 1st ed. Edited by Graham Elliott, Clive Granger and Allan Timmermann. North Holland: Elsevier, vol. 1, pp. 899-960.

Reboredo, Juan C., and Miguel A. Rivera-Castro. 2013. A wavelet decomposition approach to crude oil price and exchange rate dependence. Economic Modelling 32: 42-57. [CrossRef]

Rémillard, Bruno. 2017. Goodness-of-Fit Tests for Copulas of Multivariate Time Series. Econometrics 5: 13. [CrossRef]

Sklar, Abe. 1959. Fonctions de Répartition à n Dimensions et Leurs Marges. Publications de l'Institut Statistique de l'Université de Paris 8: 229-31.

Wu, Chih-Chiang, Huimin Chung, and Yu-Hsien Chang. 2012. The economic value of co-movement between oil price and exchange rate using copula-based GARCH models. Energy Economics 34: 270-82. [CrossRef]

(C) 2019 by the authors. Licensee MDPI, Basel, Switzerland. This article is an open access article distributed under the terms and conditions of the Creative Commons Attribution (CC BY) license (http://creativecommons.org/licenses/by/4.0/). 